\title{
The Spin-Plane Double Probe Electric Field Instrument for MMS
}

\author{
P.-A. Lindqvist • G. Olsson • R.B. Torbert • B. King • M. Granoff • D. Rau • \\ G. Needell · S. Turco · I. Dors · P. Beckman · J. Macri · C. Frost · J. Salwen · \\ A. Eriksson · L. Åhlén · Y.V. Khotyaintsev • J. Porter · K. Lappalainen · R.E. Ergun • \\ W. Wermeer $\cdot$ S. Tucker
}

Received: 10 October 2014 / Accepted: 16 October 2014 / Published online: 18 November 2014

(C) The Author(s) 2014. This article is published with open access at Springerlink.com

\begin{abstract}
The Spin-plane double probe instrument (SDP) is part of the FIELDS instrument suite of the Magnetospheric Multiscale mission (MMS). Together with the Axial double probe instrument (ADP) and the Electron Drift Instrument (EDI), SDP will measure the 3-D electric field with an accuracy of $0.5 \mathrm{mV} / \mathrm{m}$ over the frequency range from DC to $100 \mathrm{kHz}$. SDP consists of 4 biased spherical probes extended on $60 \mathrm{~m}$ long wire booms $90^{\circ}$ apart in the spin plane, giving a $120 \mathrm{~m}$ baseline for each of the two spin-plane electric field components. The mechanical and electrical design of SDP is described, together with results from ground tests and calibration of the instrument.
\end{abstract}

Keywords Magnetospheric Multiscale Mission · MMS · Electric field instrument · Spin-plane double probe $\cdot$ SDP

\section{Introduction}

The Magnetospheric Multiscale mission (MMS) is a NASA mission to study the fundamental physics of magnetic reconnection in the Earth's magnetosphere. In response to an Announcement of Opportunity in 2002 and after a Feasibility study in 2003, the Instrument

P.-A. Lindqvist $(\varangle) \cdot$ G. Olsson

Royal Institute of Technology, Stockholm, Sweden

e-mail: lindqvist@plasma.kth.se

R.B. Torbert · B. King · M. Granoff · D. Rau · G. Needell · S. Turco · I. Dors · P. Beckman · J. Macri ·

C. Frost · J. Salwen

University of New Hampshire, Durham, NH, USA

A. Eriksson · L. Åhlén · Y.V. Khotyaintsev

Swedish Institute of Space Physics, Uppsala, Sweden

J. Porter · K. Lappalainen

University of Oulu, Oulu, Finland

R.E. Ergun - W. Wermeer $\cdot$ S. Tucker

University of Colorado, Boulder, CO, USA 
suite team led by J.L. Burch of Southwest Research Institute (SwRI) was selected for flight in 2004. The proposed instrument suite, SMART (Solving Magnetospheric Acceleration, Reconnection, and Turbulence) includes instrumentation for measuring fields and particles at high accuracy and time resolution. The team providing the FIELDS suite of instrumentation is led by R.B. Torbert at the University of New Hampshire (Torbert et al. 2014, this issue). Initially planned as a contribution by the Swedish and Finnish groups, the Spin-plane Double Probe (SDP) instrument evolved into a cooperative effort between UNH, the Royal Institute of Technology (KTH), Swedish Institute of Space Physics (IRFU), the University of Oulu, and the Laboratory for Atmospheric and Space Physics (LASP) of the University of Colorado.

SDP, together with the Axial Double Probe (ADP) instrument (Ergun et al. 2014, this issue), will measure the full vector electric field from DC up to $100 \mathrm{kHz}$. The present paper gives a description of the mechanical and electrical characteristics of the instrument, together with results from the pre-flight testing and calibration.

Similar double-probe instruments with involvement of the Swedish groups at KTH and IRFU have been flown on previous missions such as the Swedish satellites Viking (Block et al. 1987), Freja (Marklund et al. 1994), and Astrid-2 (Blomberg et al. 2004), and the ESA mission Cluster (Gustafsson et al. 1997, 2001).

\section{Scientific Objectives}

The electric field is responsible for acceleration of charged plasma particles, and as such, plays a central role in the dynamics of magnetic reconnection: the universal process of converting electromagnetic energy to intense kinetic energy around astrophysical objects such as the sun, magnetized planets, and many high-energy objects such as pulsars. Measurement of the electric field component parallel to the reconnecting layer provides a direct determination of the rate of magnetic reconnection. Plasma drift different from the $\mathbf{E} \times \mathbf{B}$ drift indicates deviation from the "frozen-in" behavior, which is a signature of processes involving topological changes implied in reconnection. An unequivocal measurement of the electric field component parallel to $\mathbf{B}$ is clear evidence of acceleration processes in reconnection. Furthermore, the measurement of the electric field spectrum of plasma waves is a key to determining wave modes providing scattering of plasma particles and thus being responsible for "anomalous resistivity" that mimics resistive processes in conductive plasmas. As a critical part of the MMS instrumentation, the electric field sensors (SDP, ADP, and EDI) were charged with specific and vital requirements, as described in the FIELDS companion paper (Torbert et al. 2014, this issue). This paper describes how the SDP will meet these requirements.

\section{Summary of Instrument Characteristics}

The remainder of the paper will give a detailed description of the SDP instrument, including test and calibration. For reference, Table 1 gives a summary of the most important instrument characteristics.

The probe-probe distance is the nominal distance between the center of two opposing probes, and calculated as $2 \times$ (Hinge point + Boom cable + Preamp + Thin wire + Probe $/ 2)=2 \times(1.6+57+0.07+1.75+0.04) \mathrm{m}=120.92 \mathrm{~m}$. The effective base length for the electric field calculation is smaller than this value, due to the influence of the spacecraftboom system on the measurement (effectively "short-circuiting" the ambient electric field), an effect which will be compensated for in the ground data processing. 
Table 1 Summary of SDP instrument characteristics

Total mass per unit

Total power per unit (secondary)

Boom cable length

Boom cable diameter

Boom cable density

Boom cable surface material

Preamplifier dimensions

Preamplifier mass

Preamplifier surface material

Thin wire length

Thin wire diameter

Thin wire density

Thin wire surface material

Probe diameter

Probe mass

Probe surface material

Probe 1, 2, 3, 4 direction in $\mathrm{X}-\mathrm{Y}$ plane

Radial distance to hinge point

Probe-probe distance

Bias current range

Outer guard range

Inner guard range

Electric field measurement range

Electric field measurement resolution

Electric field measurement accuracy

Electric field frequency range
$4.30 \mathrm{~kg}$

$380 \mathrm{~mW}$

$57 \mathrm{~m}$ (nominal deployed length)

$1.55 \mathrm{~mm}$

$5.06 \mathrm{~g} / \mathrm{m}$

Silver-plated braid

$31 \mathrm{~mm}$ diameter $\times 71 \mathrm{~mm}$ length

$86 \mathrm{~g}$

DAG213 coated aluminium

$1.75 \mathrm{~m}$ (nominal deployed length)

$0.24 \mathrm{~mm}$

$0.155 \mathrm{~g} / \mathrm{m}$

Titanium

$80 \mathrm{~mm}$

$93 \mathrm{~g}$ (47 g sphere, $46 \mathrm{~g}$ yoyo)

Titanium nitride

$30,210,120,300$ degrees from $\mathrm{X}$-axis

$1.6 \mathrm{~m}$

$120.92 \mathrm{~m}$ (nominal)

$[-550,+110] \mathrm{nA}$

$[-10,+10] \mathrm{V}$ relative to probe

$[-10,+10] \mathrm{V}$ relative to probe

$\pm 500 \mathrm{mV} / \mathrm{m}$

$0.05 \mathrm{mV} / \mathrm{m}$

$0.3 \mathrm{mV} / \mathrm{m}$

DC to $100 \mathrm{kHz}$

\section{Instrument Description}

\subsection{Measurement Principle}

SDP is a double-probe instrument, measuring each component the electric field in space as the potential difference between two probes extended from the spacecraft. SDP consists of 4 probes in the spin plane, extended on $60 \mathrm{~m}$ long wire booms, and thus measures two components of the electric field vector in the spin plane. ADP measures the axial electric field in a similar manner, and the combination of SDP and ADP will give the complete electric field vector. Figure 1 shows the orientation of the SDP booms and probes on the spacecraft.

The main challenge in measuring the electric field with double probes is to get each probe to assume the potential of the ambient plasma at the probe. For any object in a plasma, the potential of the object is given by the balance of currents to and from the object. For an electric field probe in the magnetosphere, the balance of the most important currents to the probe is given by the equation

$$
I_{e}+I_{i}+I_{p h}+I_{b}=0
$$

where $I_{e}$ and $I_{i}$ are the currents carried by plasma electrons and ions hitting the probe, $I_{p h}$ is the photoemission current (zero in eclipse), and $I_{b}$ is a bias current applied to the probe to 
Fig. 1 SDP booms and probes in spacecraft coordinates

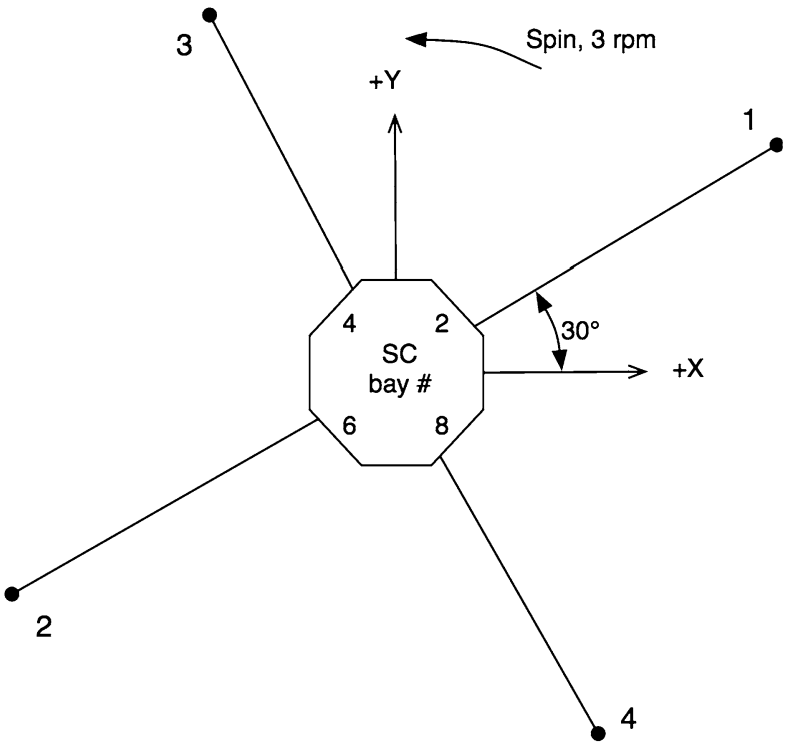

control the current balance, and thus the probe voltage (Fahleson 1967, 1974). All currents are defined as positive to the probe, implying that $I_{e}<0, I_{p h}>0$, and $I_{i}>0 . I_{b}$ can be of either sign, depending on the measuring conditions. In the low-density magnetosphere and in sunlight, the ion current can be neglected, and for zero bias current, the current balance $I_{e}+I_{p h}=0$ for a positive, spherical probe of radius $r_{p}$ can be approximated to

$$
-4 \pi r_{p}^{2} n_{e} e\left(k T_{e} / 2 \pi m_{e}\right)^{1 / 2}\left(1+e V_{p} / k T_{e}\right)+\pi r_{p}^{2} i_{p h} \exp \left(-e V_{p} / k T_{p h}\right)=0,
$$

where $n_{e}$ is the plasma density, $e$ is the elementary charge, $k$ is Boltzmann's constant, $T_{e}$ is the plasma electron temperature, $m_{e}$ is the electron mass, $V_{p}$ is the probe-plasma voltage, and $i_{p h}$ and $T_{p h}$ are the photoemissivity and photoelectron temperature of the probe (Fahleson 1967).

Figure 2 shows $I_{p h}$ and $-I_{e}$ as function of the probe voltage. The point of intersection (i.e., $I_{e}+I_{p h}=0$ ) gives the probe floating voltage $V_{f l}$, which can be many volts positive in a tenuous plasma. In order to bring the probe-plasma voltage $V_{p}$ closer to zero, and to decrease the dependence of the probe voltage on fluctuations in the plasma electron current, a negative bias current $\left(I_{b}<0\right)$ is added to Eq. (2) to give the dashed curve $-\left(I_{e}+I_{b}\right)$ in Fig. 2. Here, the intersection of the curves $I_{p h}$ and $-\left(I_{e}+I_{b}\right)$ (i.e., $I_{e}+I_{p h}+I_{b}=0$ ) gives the biased voltage of the probe, $V_{b}$, which is the desired operating point for an optimum electric field measurement.

The SDP electric field instrument is able to control the bias current $I_{b}$ to the probe between -550 and $+110 \mathrm{nA}$, and the expected nominal operational value of $I_{b}$ is between -100 and $-200 \mathrm{nA}$.

In addition to measuring the electric field, the instrument will continuously monitor the probe-spacecraft potential difference of each individual probe. This potential difference can be used as a monitor of the ambient electron flux (Pedersen et al. 2008). With the ion emitter of ASPOC (Torkar et al. 2014, this issue) operating, such measurements of the plasma density are more difficult, but still possible, albeit with lower resolution, as shown in Torkar et al. (2008). 
Fig. 2 Current-voltage curves for an unbiased (solid line) and a biased (dashed line) sunlit probe

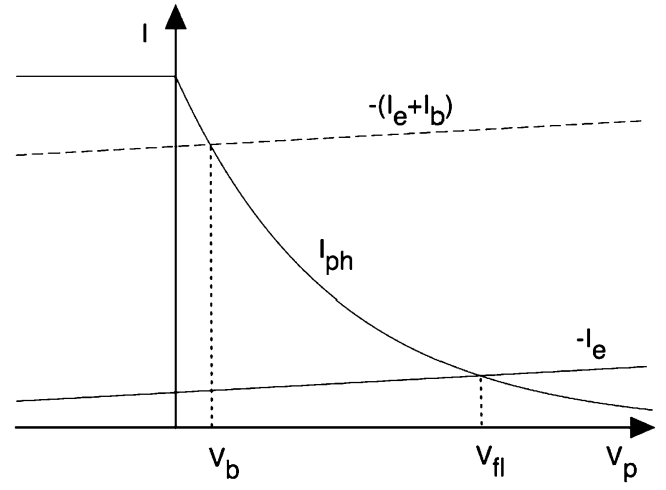

\subsection{General Overview}

Each of the four SDP units consists of a mechanical deployer in which the boom cable is stowed prior to deployment. The deployer also houses three electronics boards known as the Boom Electronics Boards (BEBs). The boom cable is extended from the deployer to nominally $57 \mathrm{~m}$ length, and is attached to a preamplifier of approximately cylindrical shape. Finally, the spherical probe is attached to the preamplifier by a thin titanium wire, length $1.75 \mathrm{~m}$. Figure 3 shows a schematic drawing indicating dimensions and potentials of the SDP deployer, boom cable, preamp, thin wire and spherical probe. The mechanical and electrical details of each of these parts are described in more detail below.

Figure 4 shows a photo of the Flight Model unit \#1 SDP unit in the stowed configuration.

SDP is a collaborative effort between a number of institutions. The main responsibilities for the different parts of SDP are given in Table 2.

\subsection{Mechanical}

The mechanical parts of SDP are the following: (1) the SDP Deployer, housing the entire instrument in the stowed configuration, (2) the Boom wire, connecting the deployer with the preamp, (3) the Preamplifier, (4) the Thin wire, connecting the Preamp with the Probe, and (5) the Probe, containing a yoyo mechanism. Each of these items is described below.

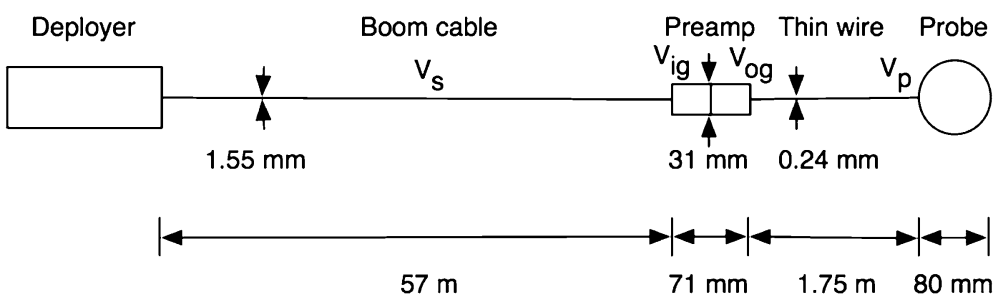

Fig. 3 Schematic drawing of the SDP instrument with dimensions of boom cable, preamp, thin wire and probe. $V_{s}, V_{i g}, V_{o g}$ and $V_{p}$ are the potentials of the spacecraft + boom cable, preamp inner guard, preamp outer guard, and probe + thin wire, respectively 
Fig. 4 Photo of FM1 SDP deployer, with the door at the front left, and the BEB housing at the back right



Table 2 Responsibilities of the institutions contributing to SDP

\begin{tabular}{ll}
\hline Institution & Responsibility \\
\hline KTH & $\begin{array}{l}\text { SDP deployer mechanical initial design, BEB electrical design and testing (for both SDP } \\
\text { and ADP), Preamp electrical design and testing, Electrical parts procurement, Boom cable } \\
\text { procurement, Thin wire procurement, Yoyo surface treatment, Overall electrical testing and } \\
\text { calibration, Yoyo thermal vacuum testing. }\end{array}$ \\
& $\begin{array}{l}\text { SDP deployer mechanical development and final design, manufacturing and testing, Motor } \\
\text { procurement, BEB mechanical housing, BEB electrical board population (for both SDP and }\end{array}$ \\
UNH & $\begin{array}{l}\text { ADP), MGSE and overall mechanical testing, Final instrument integration and } \\
\text { environmental testing. }\end{array}$ \\
& $\begin{array}{l}\text { Probe surface treatment and testing, EGSE for overall electrical testing and calibration. } \\
\text { IRFU }\end{array}$ \\
Oulu & $\begin{array}{l}\text { Probe and yoyo design, manufacturing and testing. } \\
\text { SDPign/manufacturing, Preamp electrical manufacturing. }\end{array}$ \\
LASP &
\end{tabular}

\subsubsection{Deployer}

The SDP Deployer serves as storage for the boom cable in the stowed configuration, as deployment unit during the deployment, and as mechanical housing for the Boom Electronics Boards (BEBs). Figure 5 is a schematic picture of the deployer showing the boom cable storage, the BEB housing, the door, the boom cable, the preamp, the thin wire, the spherical probe, and the interface to the spacecraft instrument deck.

Initially, the boom cable is stored between two concentric cylinders of the deployer, of which the outer cylinder is seen in Fig. 5. During deployment the boom cable is fed through the back end of the deployer by a stepper motor and emerges through the center of the deployer. Strain gauges monitor the torque in the gearbox during deployment, and an inductive sensor sensing three ferrite slugs on the main deployment wheel monitors the deployed length. A damper serves as the actual hinge point for the boom cable and is designed to damp oscillations of the boom cable resulting from spacecraft maneuvers. The damper, preamp and probe are kept in position prior to deployment by a trumpet, housed inside the inner of the two cylinders between which the boom cable is stored. Figure 6 shows a drawing of the interior of the deployer in the stowed configuration, when the thin wire between the preamp and the probe is stored in the yoyo inside the probe. 


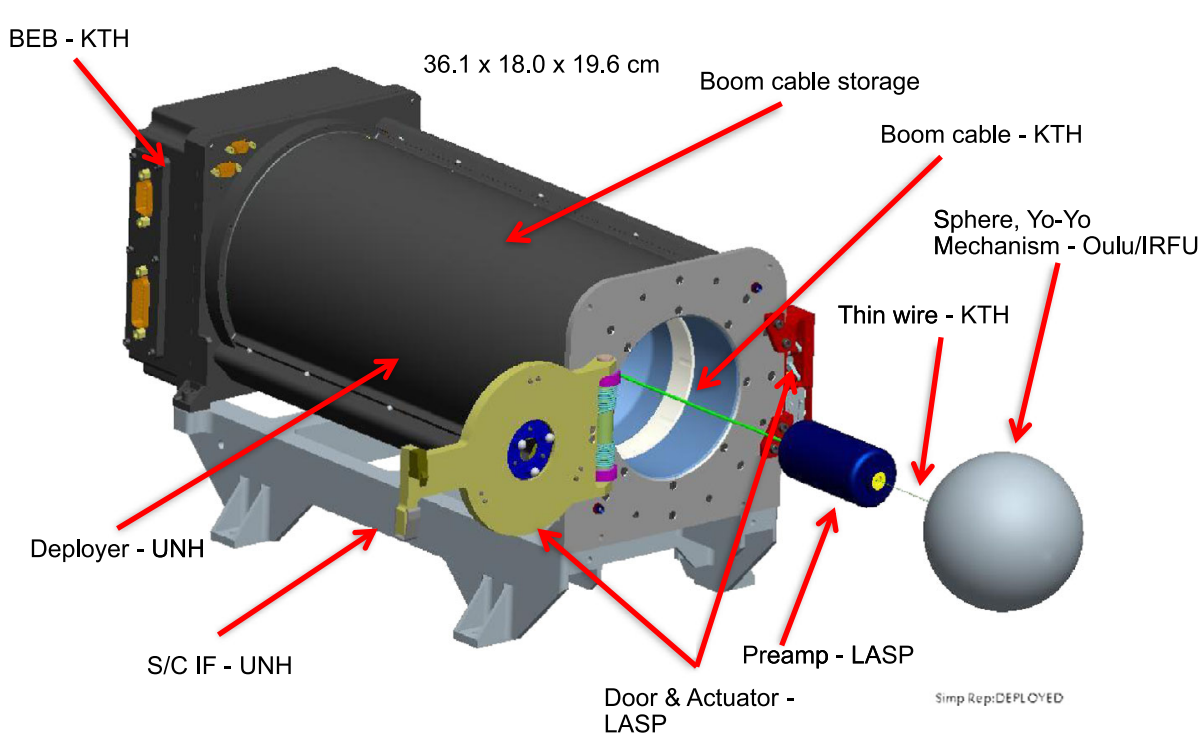

Fig. 5 Schematic drawing of the SDP deployer

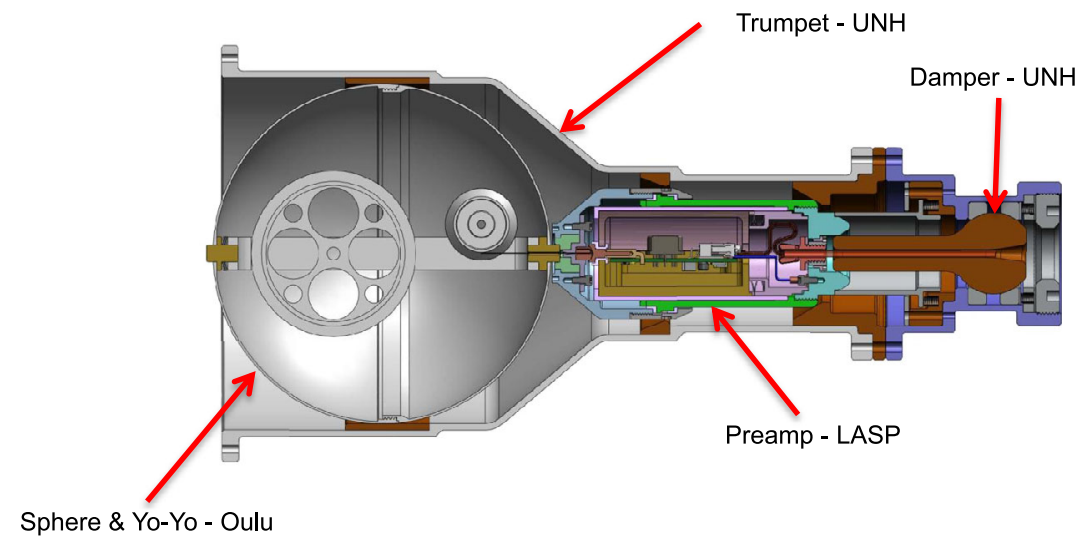

Fig. 6 Drawing of interior of deployer showing damper, preamp and probe in the stowed configuration

\subsubsection{Boom Cable}

The Boom cable constitutes the mechanical and electrical connection between the Deployer and the Preamp. It consists of 7 individual electrical conductors bundled together inside a conductive braid. The upper part of Fig. 7 shows a drawing of the boom cable, which is custom manufactured by Habia Cable in Sweden. The cable is made up of seven highstrength conductors (AWG 36) with polyimide (Kapton) insulation, six aramide (Kevlar) strands for carrying the pulling force in the cable (up to 150-200 N/strand), an aluminiumpolyimide (Kapton) foil, and a silver-plated braided shield. The lower part of Fig. 7 shows a photo of the Flight Model unit \#1 boom cable before deinsulation and soldering to the BEB connector. The diameter of each insulated conductor is $0.34 \mathrm{~mm}$ and the overall diameter of the cable is $1.55 \mathrm{~mm}$. The nominal deployed length of the boom cable is $57 \mathrm{~m}$. 

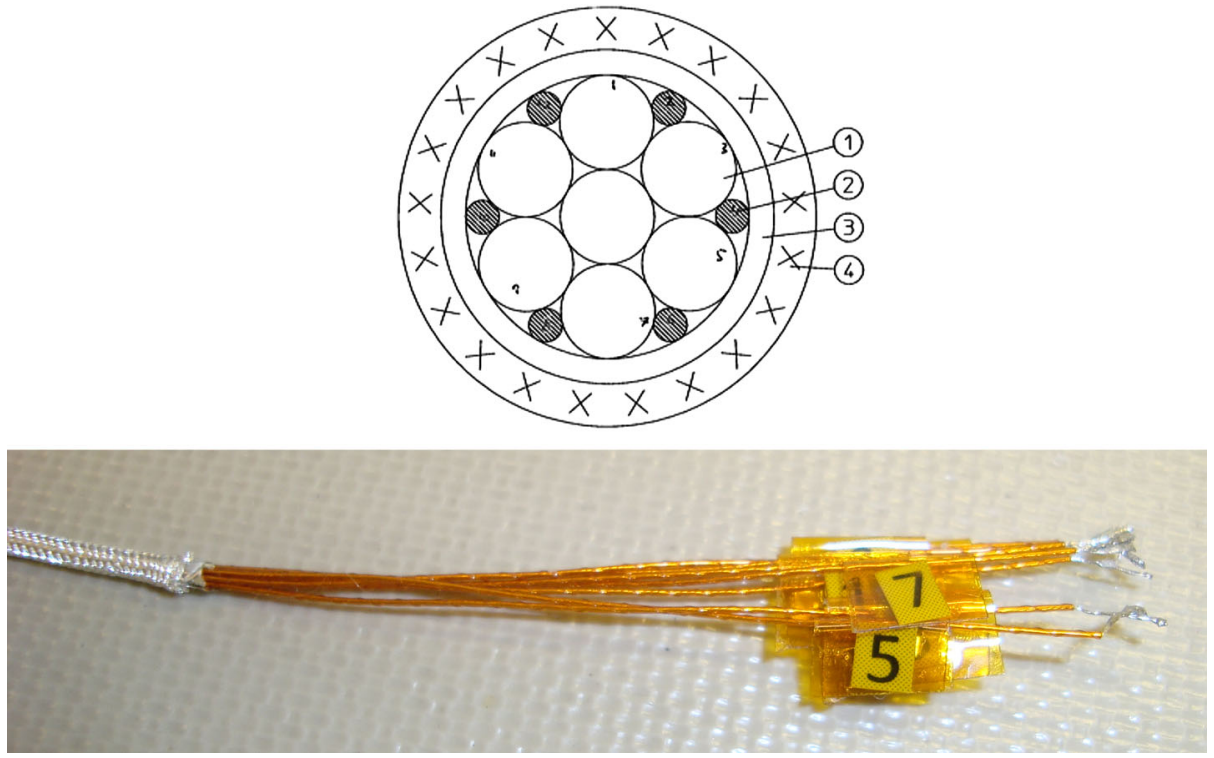

Fig. 7 The SDP boom cable. Drawing shows (1) conductor with polyimide insulation, (2) aramide strands, (3) aluminium-polyimide foil, (4) silver-plated braided shield. Photo shows the FM1 boom cable with 7 individual conductors and braided shield

\subsubsection{Preamp}

The SDP Preamplifier serves several purposes. It is the mechanical interface between the long boom cable attached to the deployer and the thin wire attached to the probe. It amplifies the electrical signal from the probe before transmission through the long boom cable to the BEB in the deployer. It serves as an electrical screen between the probe and the boom cable, designed to minimize the effects of photoelectrons on the measurement. The preamp is approximately a cylinder of $71 \mathrm{~mm}$ length and $31 \mathrm{~mm}$ diameter, made from aluminium and coated with DAG213 for improved electrical surface properties. The upper part of Fig. 8 shows a drawing of the preamplifier with the Outer and Inner Guard surfaces indicated. The guard surfaces can be individually voltage biased relative to the probe voltage $V_{p}$ to influence the flow of photoelectrons to and from the surrounding surfaces in order to optimize the electric field measurements. The outer and inner guard voltages $V_{o g}$ and $V_{i g}$ can be set in the range $V_{p} \pm 10 \mathrm{~V}$. The lower part of Fig. 8 shows a photo of the Flight Model unit \#10 preamp, attached to the boom cable and a dummy thin wire.

\subsubsection{Thin Wire}

The thin wire connects the preamp and the probe, and is initially stored in the yoyo mechanism inside the probe. The thin wire is galvanically connected to the probe and thus has the same potential as the probe. Figure 9 shows a microscope photo of the thin wire. The wire is a 19-strand Titanium wire manufactured by Titanex, Switzerland. The diameter of each strand is $0.048 \mathrm{~mm}$ and the overall diameter of the wire is $0.24 \mathrm{~mm}$. The nominal deployed length of the thin wire is $175 \mathrm{~cm}$. 
Fig. 8 The SDP preamp. Drawing shows the dimensions and the electrically separated guard surfaces. Photo shows the DAG213-coated FM10 preamp attached to the boom cable and a dummy thin wire
Fig. 9 Photo of 19-strand titanium thin wire
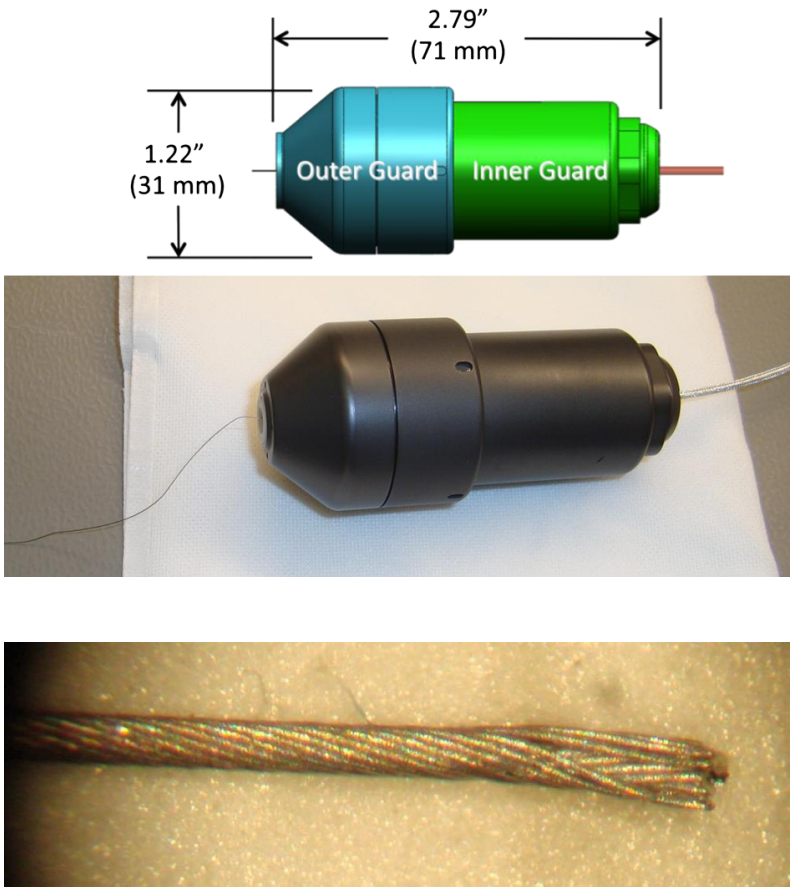

\subsubsection{Probe and Yoyo}

The spherical probe and thin wire make up the actual measuring element of the SDP instrument. The probe is kept as close as possible to the ambient plasma potential, and by measuring the potential difference between two opposing probes (probe pairs 1-2 and 3-4, respectively), it is possible to calculate the electric field along the probe-probe direction. The $80 \mathrm{~mm}$ diameter probe is made from titanium and nitrided at $800{ }^{\circ} \mathrm{C}$ to give a titanium nitride surface. The spherical shape and the highly uniform surface properties are essential for a good electric field measurement as the spacecraft spins and exposes different parts of the surface to sunlight. Figure 10 shows the probe hemispheres before and after nitriding.

Inside the probe is a yoyo mechanism for storage and controlled deployment of the thin wire connecting the probe and the preamplifier. Figure 11 shows an exploded drawing of the probe/yoyo assembly. The thin wire enters the right hemisphere (12) and is wound up on the main reel (10), which contains a leaf spring (18-19) carefully tuned to match the required force on the thin wire before, during and after deployment. The main parts are made of aluminium (Al 6082-T6) or phosphor bronze $(\mathrm{CuSn} 8)$ with the exception of the stainless steel leaf spring.

Figure 12 shows the yoyo before assembly into the probe. All surfaces of the yoyo are gold-plated to ensure good electrical conductivity. The outer (left in Figs. 11 and 12) end of the yoyo contains an internally threaded stub for electrical connection to the probe during ground testing.

\subsection{Electronics}

The electronics in the SDP instrument serve several purposes: 



Fig. 10 Eight pairs of probe hemispheres before (top) and after (bottom) nitriding

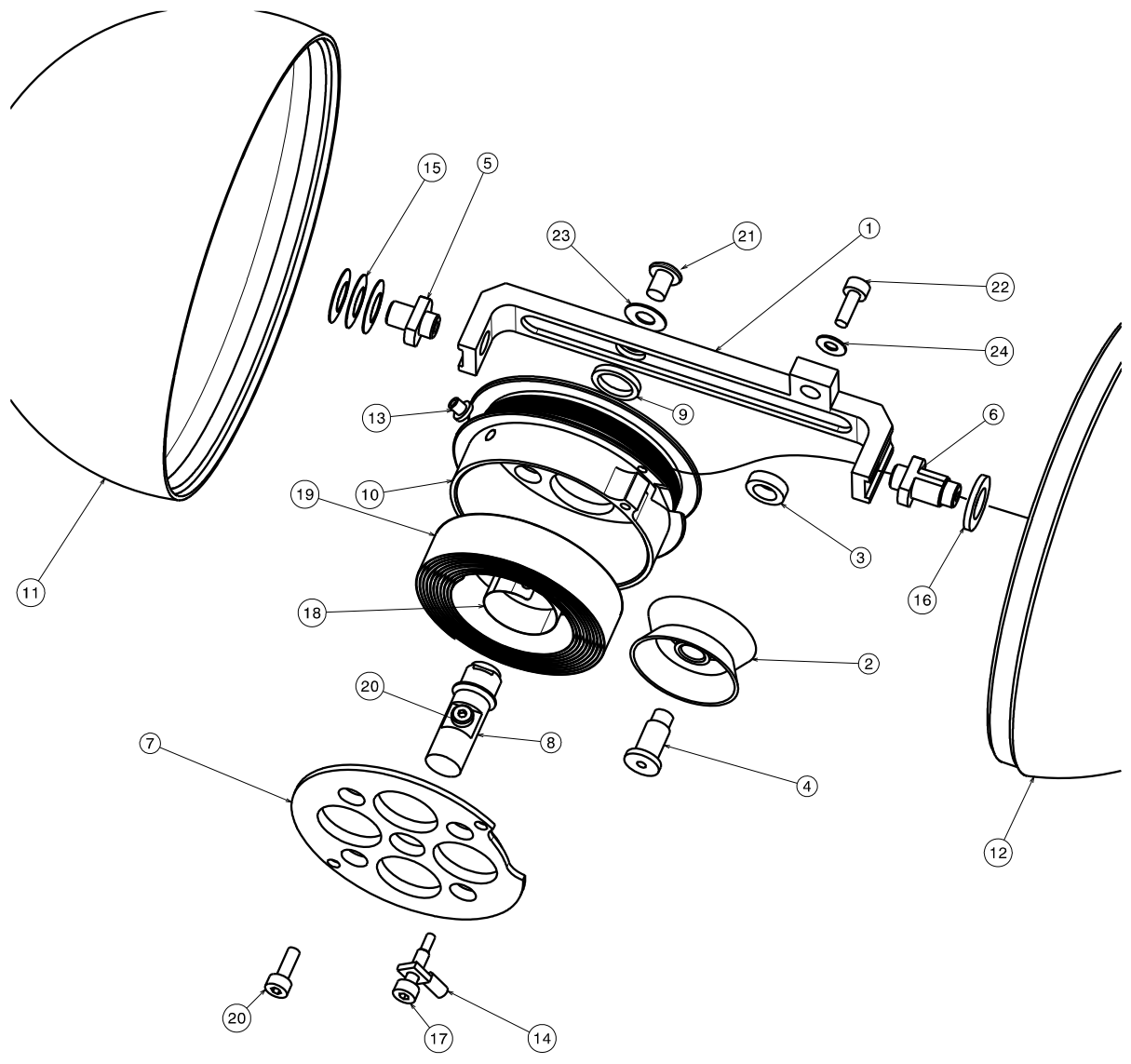

Fig. 11 Exploded drawing of probe/yoyo mechanism. Main parts are the cradle (1) supported via stubs (5, $6)$ by the outer and inner probe hemispheres $(11,12)$; the main reel $(10)$ containing a leaf spring $(18-19)$ and storing the thin wire; and a guiding wheel (2) to guide the thin wire during deployment and retraction 
Fig. 12 Photo of yoyo mechanism

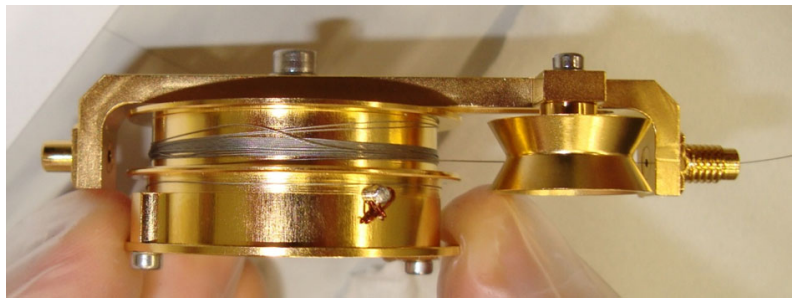

- to control the bias current $I_{b}$ to the probe in order to keep the probe near the ambient plasma potential;

- to control the preamp outer and inner guard surface potentials $\left(V_{o g}\right.$ and $\left.V_{i g}\right)$ to minimize the effect of photoelectrons;

- to amplify the probe signal $V_{p}$ before transmission through the $57 \mathrm{~m}$ boom cable;

- to output the measured analog signal to the FIELDS DSP (Digital Signal Processor) for digital filtering and sampling;

- to receive command from the FIELDS CDPU (Central Data Processing Unit) and transmit housekeeping data to the FIELDS CDPU;

- to control the stepper motor which deploys the boom cable;

- to monitor the torque in the deployment mechanism during deployment;

- to measure the boom cable deployed length as the number of turns of the main deployment wheel (independently from the length as determined by the number of steps by the stepper motor);

- to relay power from the MMS CIDP (Central Instrument Data Processor) to the HOP (High Output Paraffin) actuators for opening the deployer door and to the SDP deployment motor for boom cable deployment.

The electronics are distributed over four electronics boards, 3 boards known as the BEB (Boom Electronics Boards) located in the back of the deployer housing and 1 preamplifier board located in the cylindrical housing at the end of the boom cable. Figure 13 shows a schematic block diagram of the SDP electronics.

\subsubsection{Boom Electronics Boards (BEB)}

The Boom Electronics Boards (BEB) consists of three boards:

- the CP (Control and Power) board, with a DC/DC converter and the FPGA and DAC controller circuits, and connector to the CEB cable. The DC/DC converter frequency is $211 \mathrm{kHz}$.

- the AM (Analog and Motor) board, with the analog circuits for bias and guard control and the motor driver circuits, and connector to the CIDP power cable.

- the GT (GearTrain) board, with an inductive sensor for sensing the turns of the main wheel, and connectors to the boom cable, motor, and torque monitors. The GT board also serves as mechanical support for the gears in the deployment mechanism.

Figures 14, 15 and 16 show photos of the three individual FM17 BEB boards.

The bias current and guard voltages are set by three 16-bit DACs. $I_{b}$ can be set in the range $[-550,+110] \mathrm{nA}$, in steps of $25.28 \mathrm{pA}$. $V_{\text {og }}$ and $V_{i g}$ can be set in the range $\pm 10 \mathrm{~V}$ relative to the probe voltage $V_{p}$, in steps of $317.5 \mu \mathrm{V}$. In the event of a failure of the bias current DAC, it is possible to swap to a fourth, redundant DAC. 


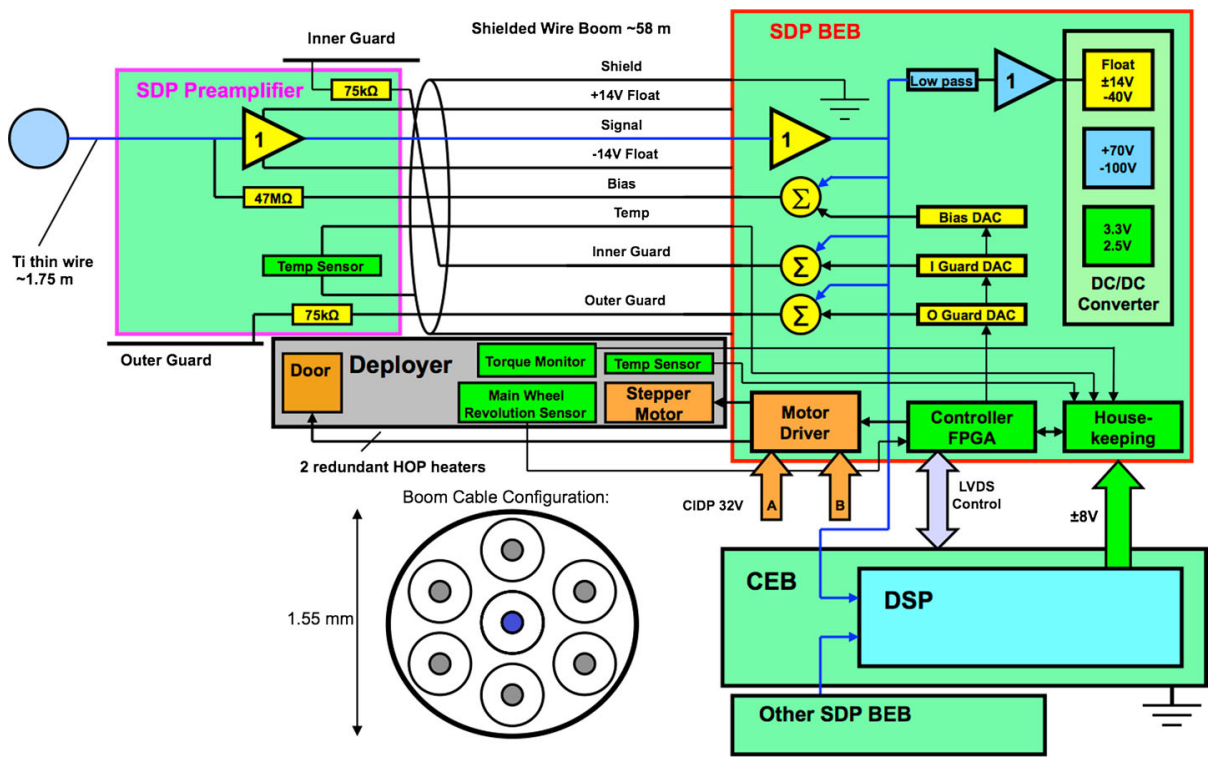

Fig. 13 Block diagram of SDP electronics (BEB and preamplifier)

Fig. 14 Photo of FM17 BEB CP board (with EMC shield removed)

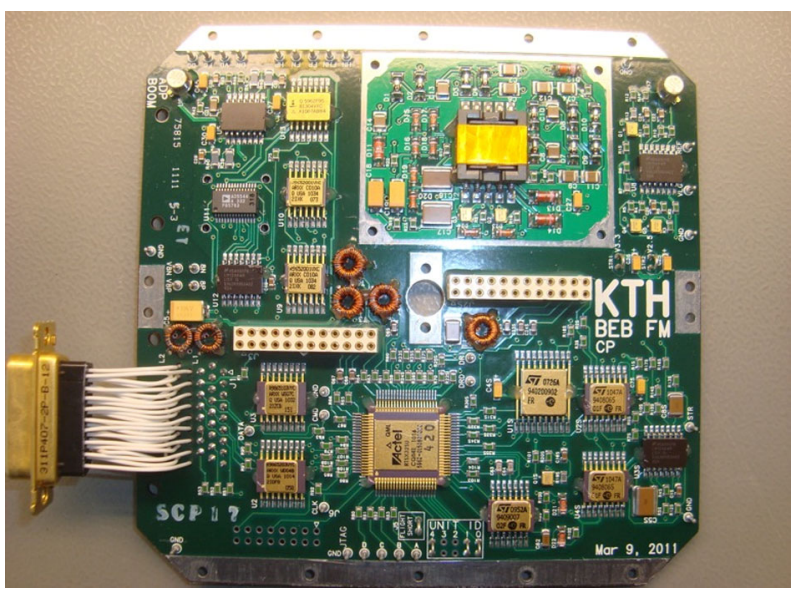

The deployment motor is a stepper motor, controlled by the BEB AM board. It is possible to power the motor without actually running the motor. The nominal deployment speed of $1 \mathrm{~cm} / \mathrm{s}$ is accomplished by running the stepper motor at 768 steps/s. Lower speeds can be used to increase the motor torque. The deployment length is controlled by commanding the BEB to run the motor for a certain number of steps, where $1 \mathrm{~m}$ corresponds to 76,800 steps. The deployment is normally stopped automatically by the BEB when the number of steps has been reached, but the BEB also monitors the deployment length by two independent means. The inductive sensor on the GT board will sense 3 pulses per revolution of the main deployment wheel and any anomaly can be used to cause deployment to stop. Strain gauges in the deployer sense the torque in the mechanism and a torque exceeding a chosen limit can also terminate deployment. The inductive sensor counts and the torque value are read and 
Fig. 15 Photo of FM17 BEB AM board



Fig. 16 Photo of FM17 BEB GT board with inductive sensor

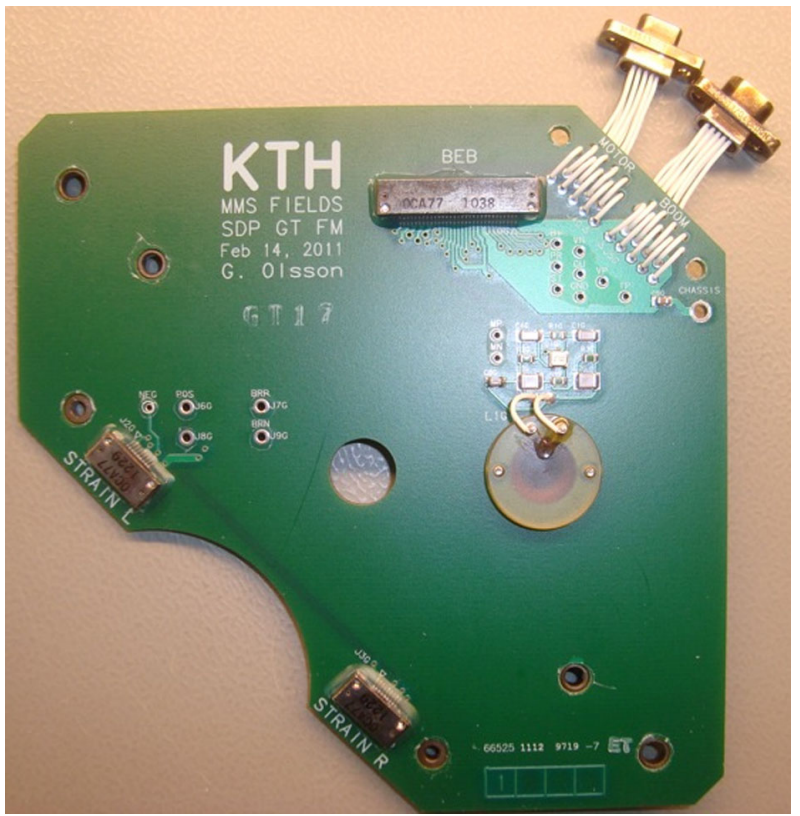

monitored by the flight software in the CEB, which determines the conditions under which to send a premature stop deployment command to the BEB.

The ADP instrument contains a similar arrangement of Boom Electronics Boards for control of the ADP bias current and voltages (Ergun et al. 2014, this issue). The differences are that ADP has no GT board, and the ADP BEB boards control 3 guard voltages instead of 2 and do not contain any motor control circuitry. 
Fig. 17 Photo of FM30 preamp board. The boom cable attaches to the right



\subsubsection{Preamplifier}

The preamplifier electronics are located in the preamplifier housing at the end of the boom cable. The preamplifier amplifies the signal entering through the thin wire connected to the probe and passes it on to the BEB through the boom cable central conductor. It relays the bias current to the probe and the outer and inner guard voltages to the preamp housing, and it also contains a temperature sensor. Figure 17 shows a photo of the preamplifier board.

\section{Ground Testing and Calibration}

All parts of SDP, mechanical and electrical, have undergone extensive testing and calibration at the contributing institutions. In addition, the electric field measurements will be calibrated in flight by comparisons with other measurements on the satellite.

\subsection{Mechanical Testing}

\subsubsection{Probe/Yoyo Testing}

The probe and yoyo parts are manufactured by the University of Oulu. The probe is nitrided and the photoelectric surface properties of each probe is characterized before selection and matching of probe hemispheres for flight configuration. The yoyo parts are gold plated before assembling into the yoyo, which is then subjected to pull tests at Oulu and KTH to determine and verify the force characteristics.

Probe Sphere Surface Tests After nitriding at the company LoosTec, Sweden, each probe hemisphere is visually inspected at IRFU for uniformity of the Titanium nitride surface. Measuring the real surface photoemission during exposure to realistic solar UV and Xray irradiation is difficult, but UV reflectance tests are done and used as a proxy to the photoemission properties. The main goal is to achieve uniformity over the surface, and to match probes with similar characteristics to form opposing pairs on the spacecraft. Figure 18 shows the setup used for the UV reflectance measurements and Fig. 19 shows the results.

The reflectance of 15 points on the hemisphere is measured as function of wavelength from 200 to $300 \mathrm{~nm}$, shown as vertical strips in the right part of Fig. 19. The same results are plotted in the top left of the figure (cyan curves), together with the mean (black curve) and $\pm 5 \sigma$ (red curves). The lower left of the figure shows the relative standard deviation $(\sigma /\langle$ reflectance $\rangle)$ as function of wavelength, in percent, and the numbers $\mathrm{m}$ and $\mathrm{p}$ at the top right of the figure are the mean reflectance and the mean relative standard deviation over 
Fig. 18 Probe hemisphere mounted on bracket for UV reflectance measurements
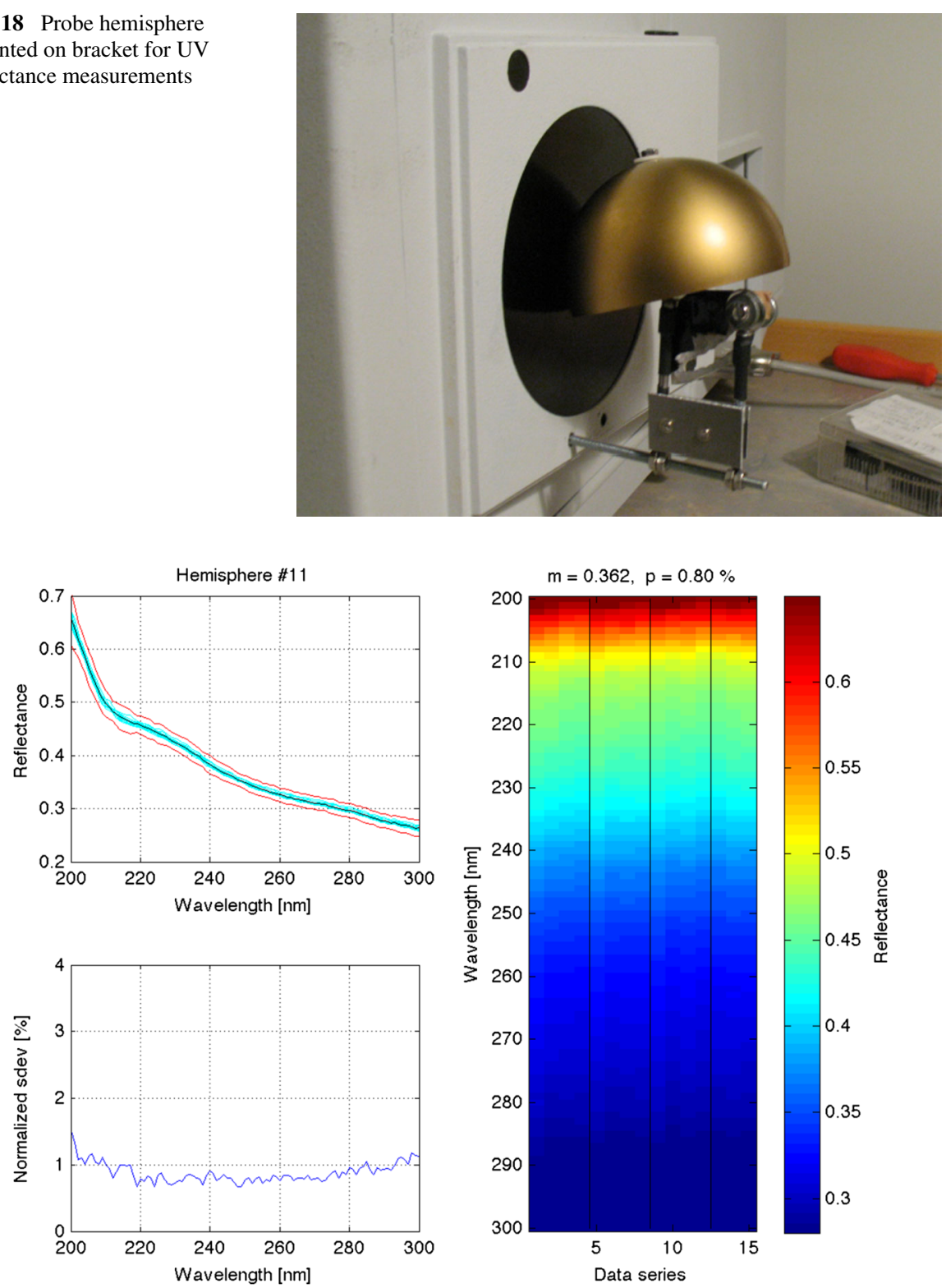

Fig. 19 Results of UV reflectance measurements on hemisphere 11 of probe A1. See text for explanation

the wavelength range $220-280 \mathrm{~nm}$. Low $p$ indicates a uniform surface and $\mathrm{m}$ is used to match probes with similar reflectance. The probes selected for flight have $p$ in the range $0.63-3.07 \%$ and $\mathrm{m}$ in the range $0.313-0.415$.

Probe Yoyo Pull Tests The yoyo is designed and manufactured so that the force needed to deploy the thin wire during the commissioning and keep it deployed thereafter matches the plan for deployment of the SDP boom cable and the associated spin-up maneuvers. After 


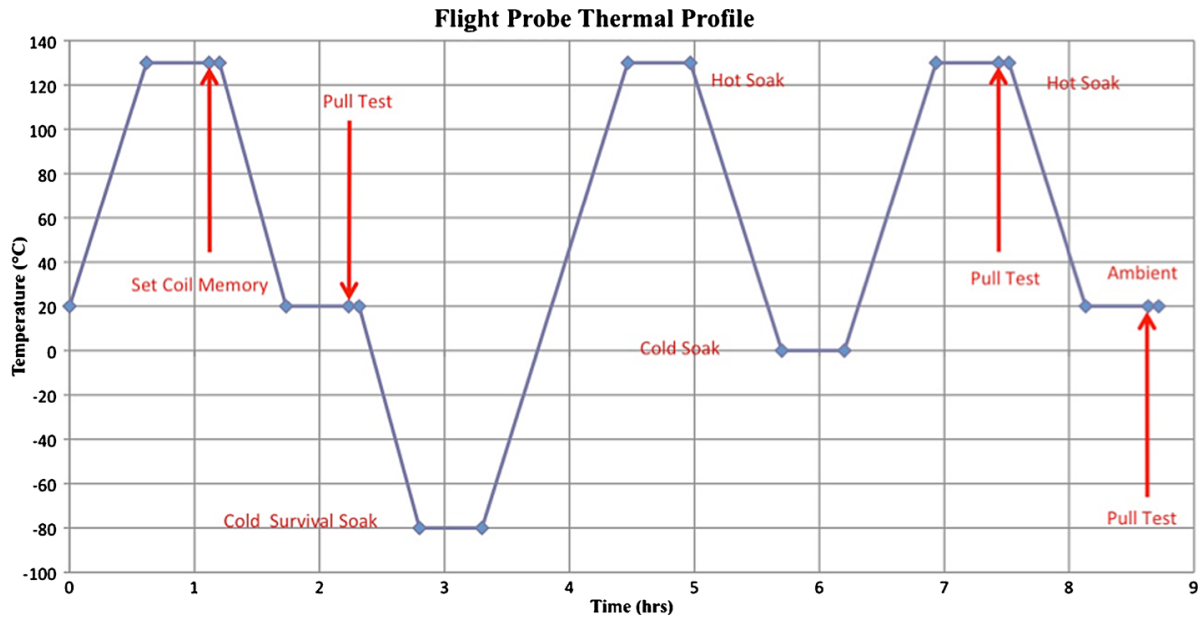

Fig. 20 Initial thermal cycling and pull tests of yoyo mechanism

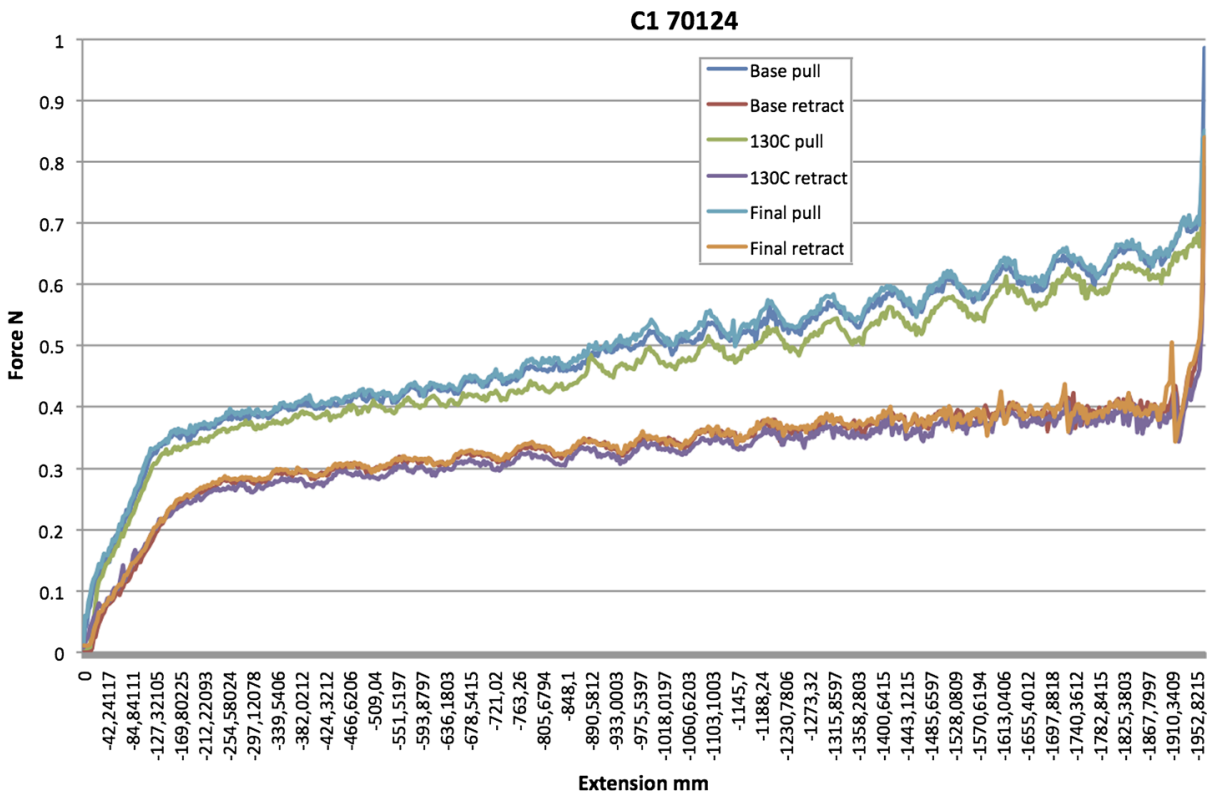

Fig. 21 Pull test of probe C1, yoyo \#70124 showing forces during deployment and retraction of the thin wire. Cf. Fig. 35 for the tension experienced in the thin wire during SDP boom cable deployment and associates spin-ups

assembly, the probe is subjected to thermal cycling between -80 and $+130{ }^{\circ} \mathrm{C}$, including pull tests, at the University of Oulu. The temperature profile is given in Fig. 20.

The first deployment at $130{ }^{\circ} \mathrm{C}$ is to condition the leaf spring inside the yoyo. Subsequent deployments and retractions (indicated by "Pull Test" in Fig. 20) are to verify that the forces in the yoyo are consistent with the forces expected during the instrument commissioning. The result of the tests for probe $\mathrm{C} 1$ is seen in Fig. 21. 
Fig. 22 Temperature profile and setup of preamp thermal workmanship test

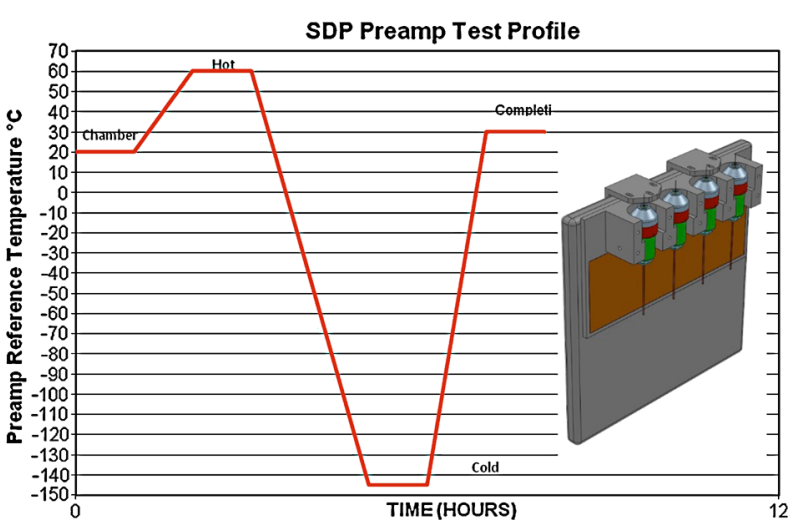

The wavy nature of the curves in Fig. 21 is due to the individual turns of the main reel in the yoyo. A similar pull test but with lesser accuracy is also done at $\mathrm{KTH}$, in vacuum, at $20{ }^{\circ} \mathrm{C}$ and $130{ }^{\circ} \mathrm{C}$, to verify that the yoyo functions as expected also under vacuum conditions.

\subsubsection{Preamp Testing}

After manufacturing at LASP, the preamplifiers are subjected to a thermal workmanship test at UNH. Four preamps are simultaneously subjected to temperatures between -145 and $+40{ }^{\circ} \mathrm{C}$ in a thermal vacuum chamber, using a temperature profile and test setup seen in Fig. 22.

The electric functionality of the preamps is verified before and after the test.

\subsubsection{Deployer Testing}

After integration of the SDP deployer with the BEB, boom cable, preamp and probe, each FM unit is subjected to a number of electrical and mechanical tests. The component level testing of SDP includes the following tests:

- Full functional test (FFT) at ambient temperature and pressure, including electronic checkout, door deployment, full length boom cable deployment, probe/yoyo pull test and boom cable stowage;

- EMI/EMC test including magnetics;

- Vibration tests, three-axis;

- Repeated FFT at ambient;

- Thermal vacuum bakeout at $+60{ }^{\circ} \mathrm{C}$;

- FFT in thermal vacuum, including electronic checkout, cold and hot door deployment, hot and cold full length boom cable deployment, outgassing test, probe/yoyo pull test and boom cable stowage.

The thermal vacuum door deployment is done by energizing a High Ouput Paraffin (HOP) actuator at -25 and $+50{ }^{\circ} \mathrm{C}$. The thermal vacuum boom cable deployments are done at +40 and $-10{ }^{\circ} \mathrm{C}$. The deployment of the boom cable is done in pairs. Figure 23 shows a drawing of the mounting of 2 SDP deployers in the thermal vacuum chamber, including an intricate "elevator" system for catching the probe and preamp during the first motion of the deployment. 
Fig. 23 Drawing of the SDP deployer thermal vacuum test setup, including elevator for catching the probe/preamp
Fig. 24 SDP FM2 and FM7 in thermal vacuum chamber, after first motion deployment, showing probes, collecting buckets, and deployers
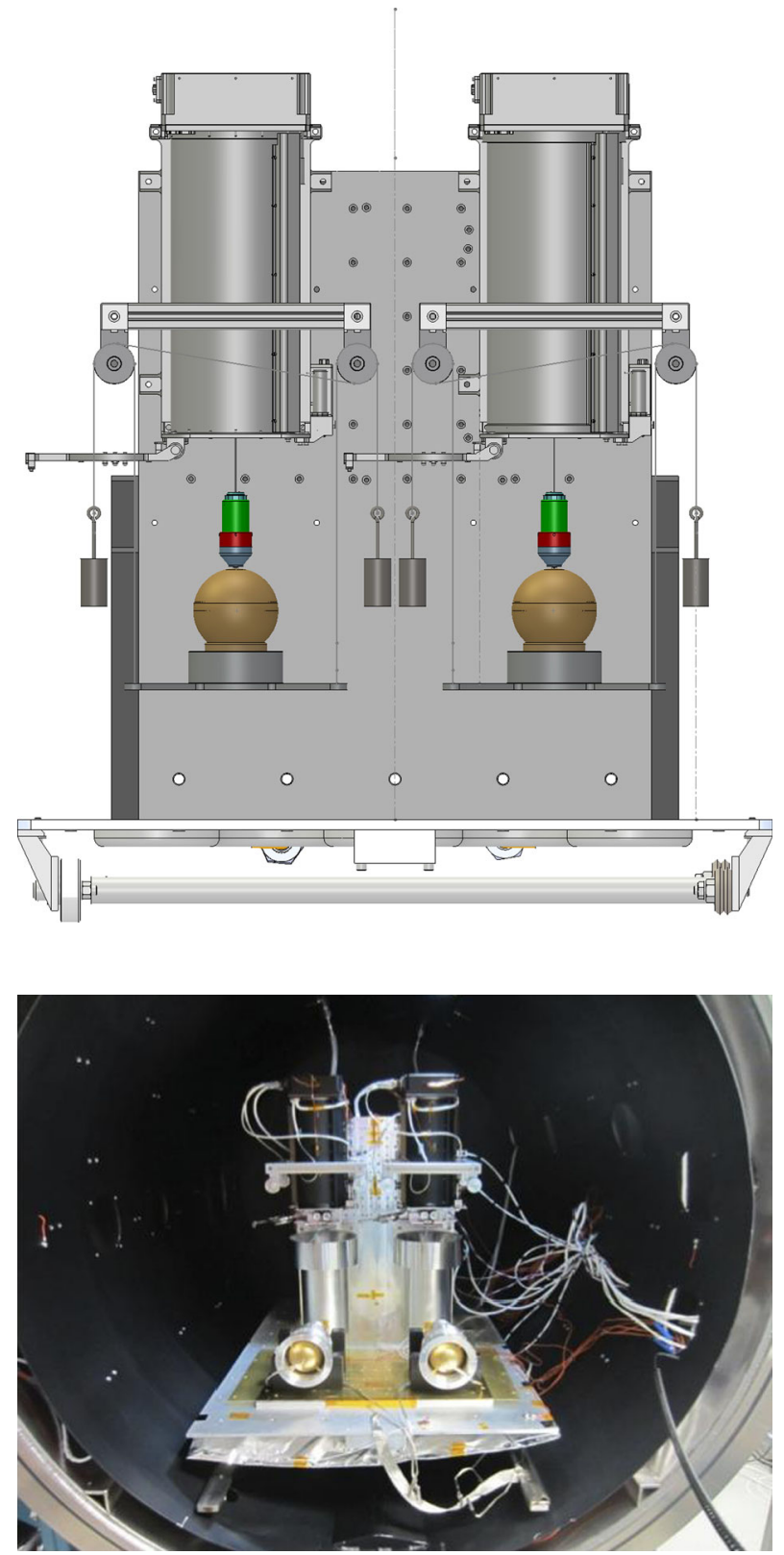

Figure 24 shows SDP units FM2 and FM7 in the thermal vacuum chamber after first motion deployment $(30 \mathrm{~cm})$, with each probe visible in front of a cylindrical bucket below each of the deployers. The function of the bucket is to collect the $57 \mathrm{~m}$ of boom cable as it is deployed. The deployment is carried out in 4 steps, deploying between 5 and $19 \mathrm{~m}$ in each step.

Figure 25 shows the measurement of the torque monitor built into the SDP to check that the deployment runs smoothly. This measurement is available onboard in realtime during 

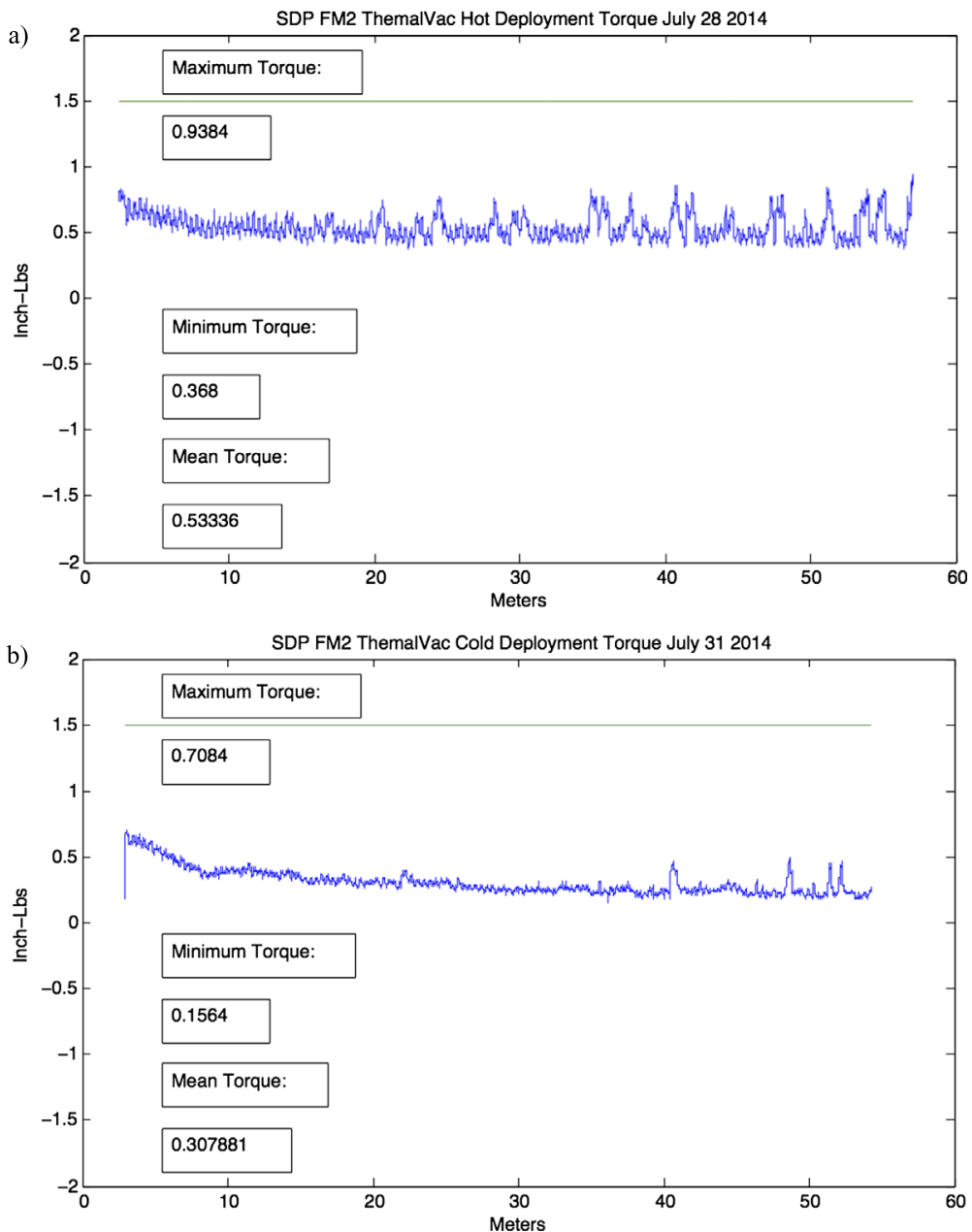

Fig. 25 Torque measured by the internal SDP torque monitor during hot (a) and cold (b) deployments of SDP FM2

SDP deployment, and can be used to automatically stop the deployment in case of deviations from a nominal range.

\subsection{Electrical Testing and Calibration}

\subsubsection{Preamplifier/Cable Testing}

Electrical tests of the preamplifier, attached to a $60 \mathrm{~m}$ boom cable, were performed at KTH. Tests were done of the connectivity and cable ordering, and of the capacitances between different combinations of the 7 cable conductors. The tests included a measurement of the maximum distortion-free output signal amplitude as function of frequency between 2 and $100 \mathrm{kHz}$. The results of these tests for all 16 flight units are given by the thin lines in Fig. 26. All measurements fulfill the minimum requirements as given by the thick line. 


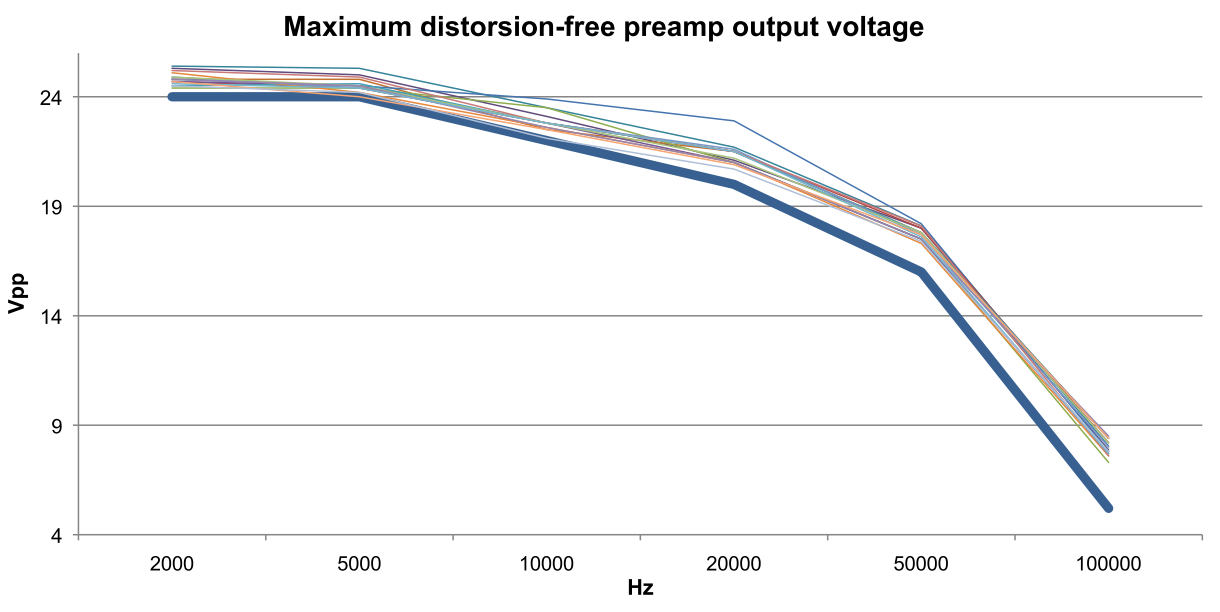

Fig. 26 Results of preamp maximum output voltage testing. All measurements fulfill the minimum requirements as given by the thick line

\subsubsection{BEB/Cable/Preamplifier Testing and Calibration}

The main electrical testing of the BEB/cable/preamplifier system was done at IRFU. This included Thermal workmanship cycling tests and Full thermal verification and calibration tests of each individual BEB unit together with its matching boom cable and preamplifier.

In the Thermal workmanship tests, the BEB was first connected to an engineering model (EM) cable/preamp assembly and tested at room temperature. Then the BEB was subjected to a thermal cycling at $+60,-35,+60,-35,+60,-35$, and $+30{ }^{\circ} \mathrm{C}$, after which it was again tested at room temperature. The tests performed before and after the thermal workmanship cycling were the following:

- Guard voltage tests,

- Bias current tests,

- Bias current $100 \mathrm{MOhm}$ tests,

- Transfer function tests,

- Large signal transfer function tests,

- Motor tests,

- Houskeeping tests,

- Voltage range tests.

The Full thermal verification tests were done in two stages, both with each individual BEB connected to its corresponding flight model (FM) cable/preamp assembly. In the first stage, the BEB was located in the thermal chamber, and the preamp was kept at room temperature and located in a specially designed rectangular stimuli box. In the second stage the preamp was in the thermal chamber and the BEB was kept at room temperature. Both stages of the full thermal verification were done at temperatures of $+50,+20,0$, and $-25^{\circ} \mathrm{C}$. The tests performed during full thermal verification were the following:

- Guard voltage tests,

- Bias current tests,

- Bias current $100 \mathrm{MOhm}$ tests,

- Transfer function tests (only in stage 1), 


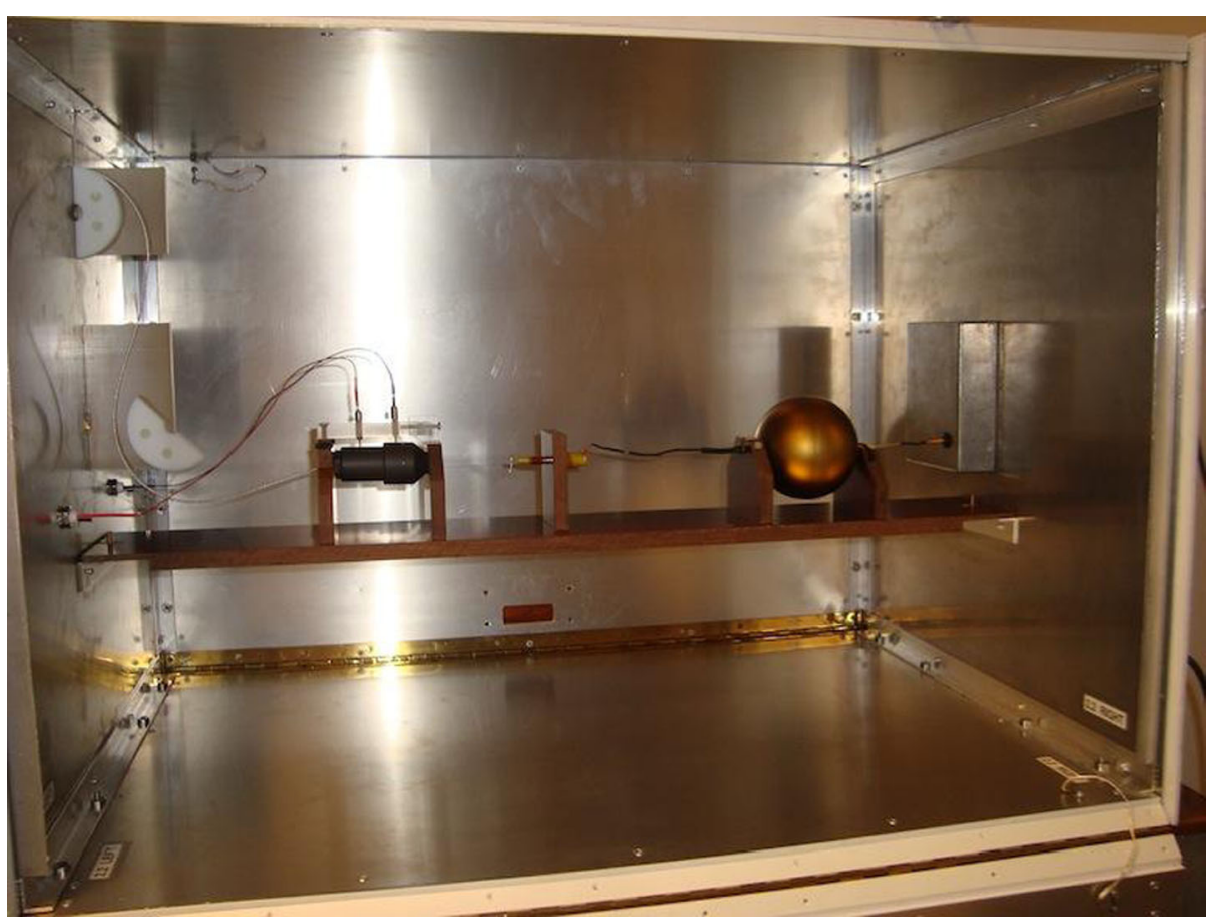

Fig. 27 The FM2 preamp mounted in the test stimuli box at IRFU for thermal verification testing, stage 1

- Network analyzer transfer function tests,

- Large signal transfer function tests (only in stage 1),

- Motor tests (only in stage 1),

- Houskeeping tests,

- Voltage range tests (only in stage 1).

The stimuli box used for the tests in stage 1 is seen in Fig. 27. The boom cable enters from the left and terminates in the preamp. A short thin wire from the preamp is connected to the probe at the right. Voltages can be applied to the probe through various impedances via the box at the far right, and to the inner and outer guards through the spring-loaded electrodes above the preamp. Finally, the entire inner surface of the stimuli box can be either grounded or connected to the same input signal as the probe.

For the tests in stage 2, with the preamp in the thermal chamber, a simpler setup is used, seen in Fig. 28. To get a reasonable impedance in the boom cable, it is fully extended and mounted in a winding pattern along the cleanroom wall.

Figures 29, 30 and 31 show some of the results of the full thermal verification and calibration tests. Figure 29 shows the calibration curve of the bias current calibration on the FM8 BEB/cable/preamp assembly at $20^{\circ} \mathrm{C}$ and with an input signal of $0 \mathrm{~V}$ to the probe. The measured value (y-axis) agrees well with the set value (x-axis); for this particular unit a least-squares fit to the data gives the relation

$$
I_{\text {bias,measured }}=0.999257 \cdot I_{\text {bias, set }}+0.468 \mathrm{nA} \text {. }
$$


Fig. 28 The FM1 preamp mounted in the thermal chamber at IRFU for thermal verification testing, stage 2

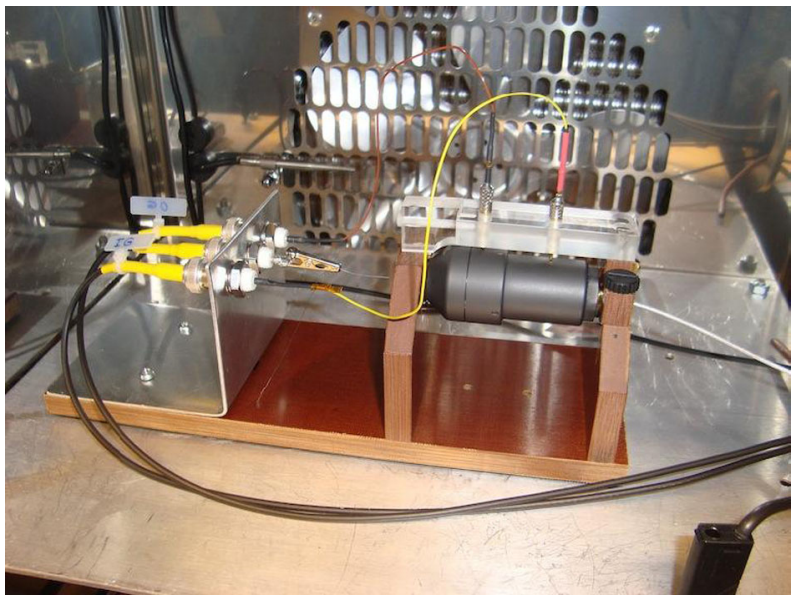

FM8 bias calibration, $20^{\circ} \mathrm{C}, 0 \mathrm{~V}$

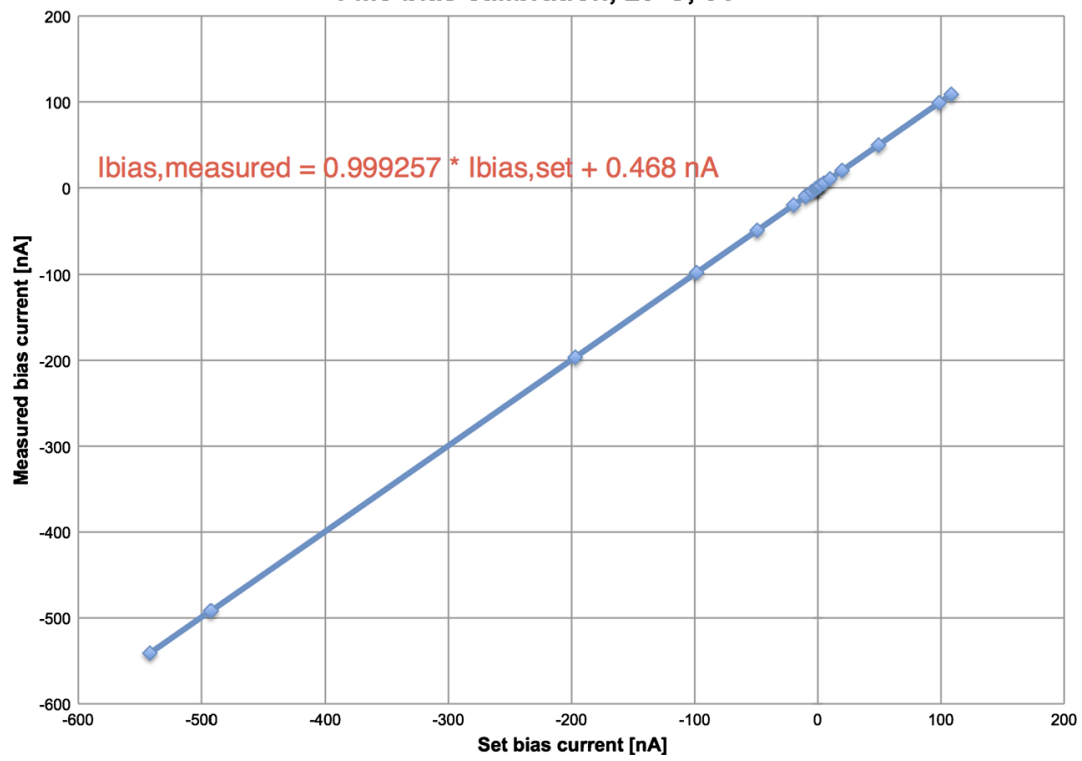

Fig. 29 Bias current calibration curve for $\mathrm{FM} 8,20{ }^{\circ} \mathrm{C}, 0 \mathrm{~V}$ input signal

Similar curves and calibration coefficients are available for the bias current (both unswapped and swapped DAC), and for the inner and outer guard voltages for all FM assemblies, for temperatures of $+50,+20,0$, and $-25{ }^{\circ} \mathrm{C}$ and probe input voltages of $\pm 50, \pm 10$ and $0 \mathrm{~V}$.

Figures 30-31 show a summary of the network analyzer transfer function tests on the FM13-18 BEB/cable/preamp assemblies. The figures show the gain and phase from $3 \mathrm{~Hz}$ to $250 \mathrm{kHz}$ for a signal fed to the probe through two different input impedances: $10 \mathrm{k} \Omega$ and $10 \mathrm{M} \Omega$ in parallel with $10 \mathrm{pF}$. These particular tests were done at $20{ }^{\circ} \mathrm{C}$, with the input signal sent both to the probe and to the inner surface of the stimuli box. Similar curves are 
FM13-18 S-BEB Gain Plots with $10 \mathrm{k} \Omega$ and $10 \mathrm{M} \Omega / / 10 \mathrm{pF}$ Loads

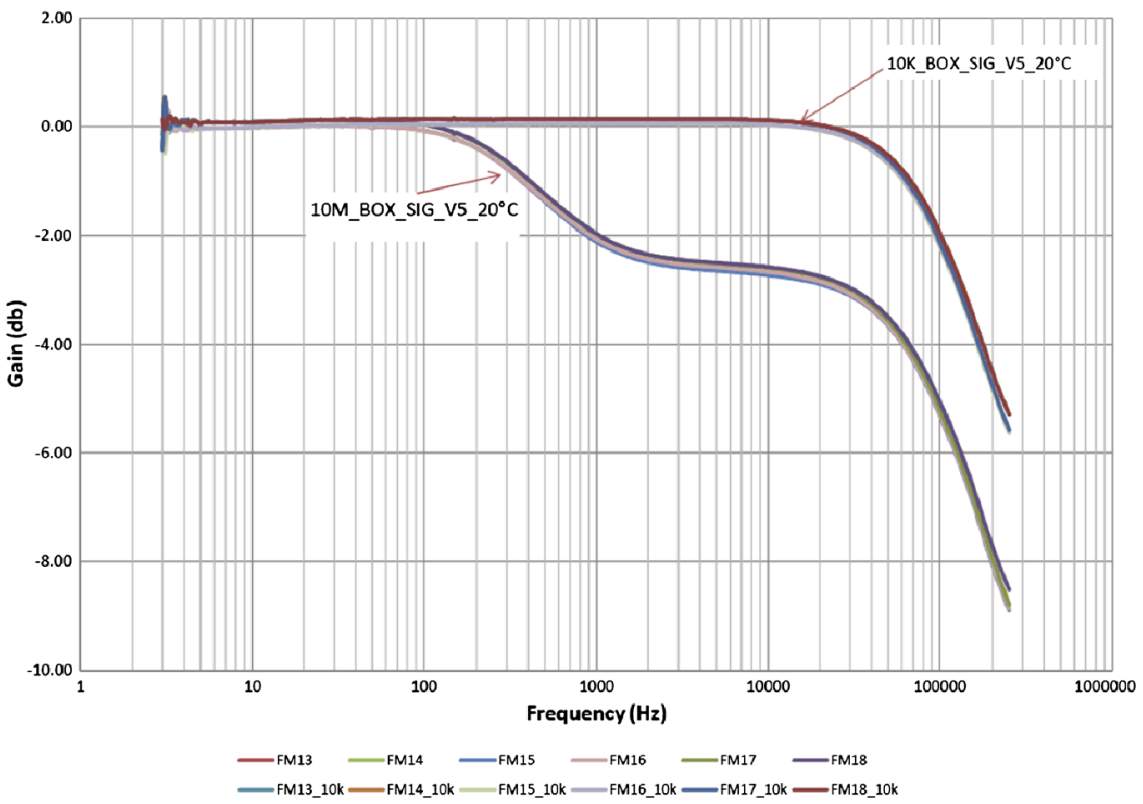

Fig. 30 Gain plots of the transfer function for FM13-FM18 in IRFU stimuli box at $20{ }^{\circ} \mathrm{C}$, for two input impedances: $10 \mathrm{k} \Omega$ and $10 \mathrm{M} \Omega / / 10 \mathrm{pF}$

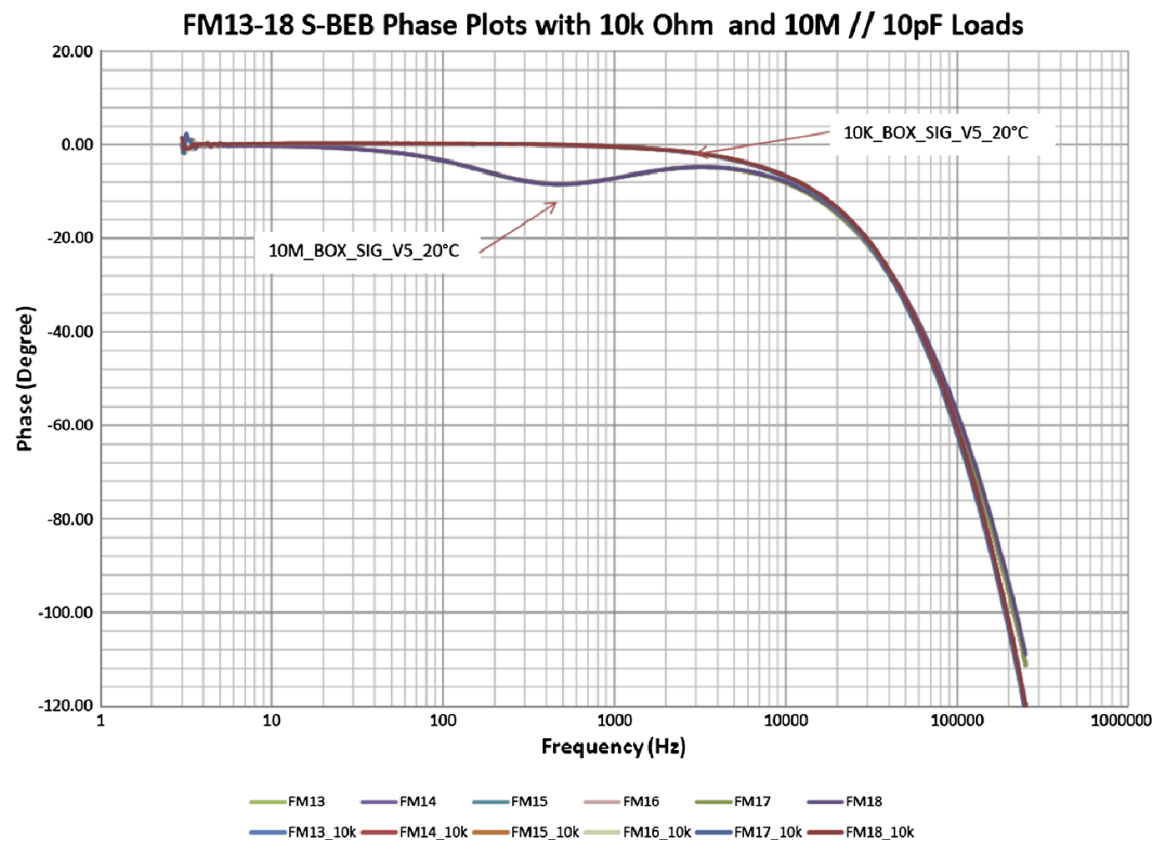

Fig. 31 Phase plots of the transfer function for FM13-FM18 in IRFU stimuli box at $20{ }^{\circ} \mathrm{C}$, for two input impedances: $10 \mathrm{k} \Omega$ and $10 \mathrm{M} \Omega / / 10 \mathrm{pF}$ 
available for all FM assemblies, for temperatures of $+50,+20,0$, and $-25^{\circ} \mathrm{C}$, and with the stimuli box either grounded or receiving signal.

The tests at IRFU were done with the probe and preamp located in a rectangular stimuli box, which enables verification of all instrument functionality and good calibration of bias currents and guard voltages. For a better calibration of the phase/gain characteristics, a more elaborate setup was used, as described in the next section. Figures 30 and 31 above may be compared to Fig. 33 to compare the results of similar calibrations in the two different setups.

Similar tests and calibrations to those done at IRFU on the SDP BEB/cable/preamp assemblies were also done on the ADP BEB assemblies using the same test equipment. For these tests, an EM ADP boom cable and preamp was used, since no FM hardware was available, and no stimuli box was used to enclose the ADP EM preamp. Final calibrations of the ADP including the Receiving Element (RE) were done at LASP (Ergun et al. 2014, this issue).

\subsubsection{Full System Testing and Calibration}

In order to test one flight unit of the complete SDP in more realistic conditions than those possible for the main testing of the BEB/cable/preamplifier, a special test was done on Flight Model \#17 in the EMC chamber at IRFU. This chamber is an electrically shielded room of about $10 \times 10 \times 10 \mathrm{~m}^{3}$ size. A metal cylinder of $6 \mathrm{~m}$ length and $80 \mathrm{~cm}$ diameter was mounted along one wall of the EMC chamber. The FM17 preamp was connected to an EM probe with the thin Titanium wire $(175 \mathrm{~cm}$ length) and mounted along the axis of the cylinder, with the probe centered between the cylinder ends. The boom cable from the preamp continued axially out from the cylinder and was extended to its full length (approximately $60 \mathrm{~m}$ ) by mounting on special reels along the remaining three walls of the chamber. The other end of the boom cable was connected to the FM17 BEB. A coaxial cable was fed in along the axis of the opposite end of the cylinder and was used to stimulate the probe via various RC networks. Figure 32 shows a picture of the cylinder with boom cable (in the white cable holder), preamp (in near plastic bag), thin wire, and probe (in far plastic bag). Also seen are parts of the EGSE at the far end of the cylinder.

The tests done were of two types: transfer function tests and noise tests. In the transfer function tests, the probe was stimulated via an RC network of between $10 \mathrm{k} \Omega$ and $20 \mathrm{M} \Omega$ in parallel with 0-23.6 pF. Signal could be fed to the probe only, or the cylinder only, or both probe and cylinder. A typical transfer function using $R=10 \mathrm{M} \Omega$ and $C=10.4 \mathrm{pF}$, with signal on both probe and cylinder is shown in Fig. 33.

Figure 33 should be compared with Figs. 30-31 where the same unit was tested in the less realistic setup during the thermal verification tests at IRFU.

In the noise tests, the probe was grounded through $10 \mathrm{k} \Omega$ or $5.1 \mathrm{M} \Omega$ and the noise at the analog output of the BEB was measured with the BEB switched off (for background noise) and with the BEB on. Figure 34 shows the results of such measurements, and it can be seen that the instrument noise barely rises above the background noise, and is well below the requirements, as indicated by the black line $\left(1 \mu \mathrm{V} / \mathrm{Hz}^{1 / 2}\right.$ at $\left.10 \mathrm{kHz}\right)$. The spikes above $1000 \mathrm{nV} / \mathrm{Hz}^{1 / 2}$ at multiples of $31.5 \mathrm{kHz}$ are ambient noise from the measuring equipment, present also in the background, and the spike at $211 \mathrm{kHz}$ from the BEB DC-DC converter is outside the measurement range. Peaks at odd multiples of $50 \mathrm{~Hz}$ are due to the utility frequency used in Sweden. 


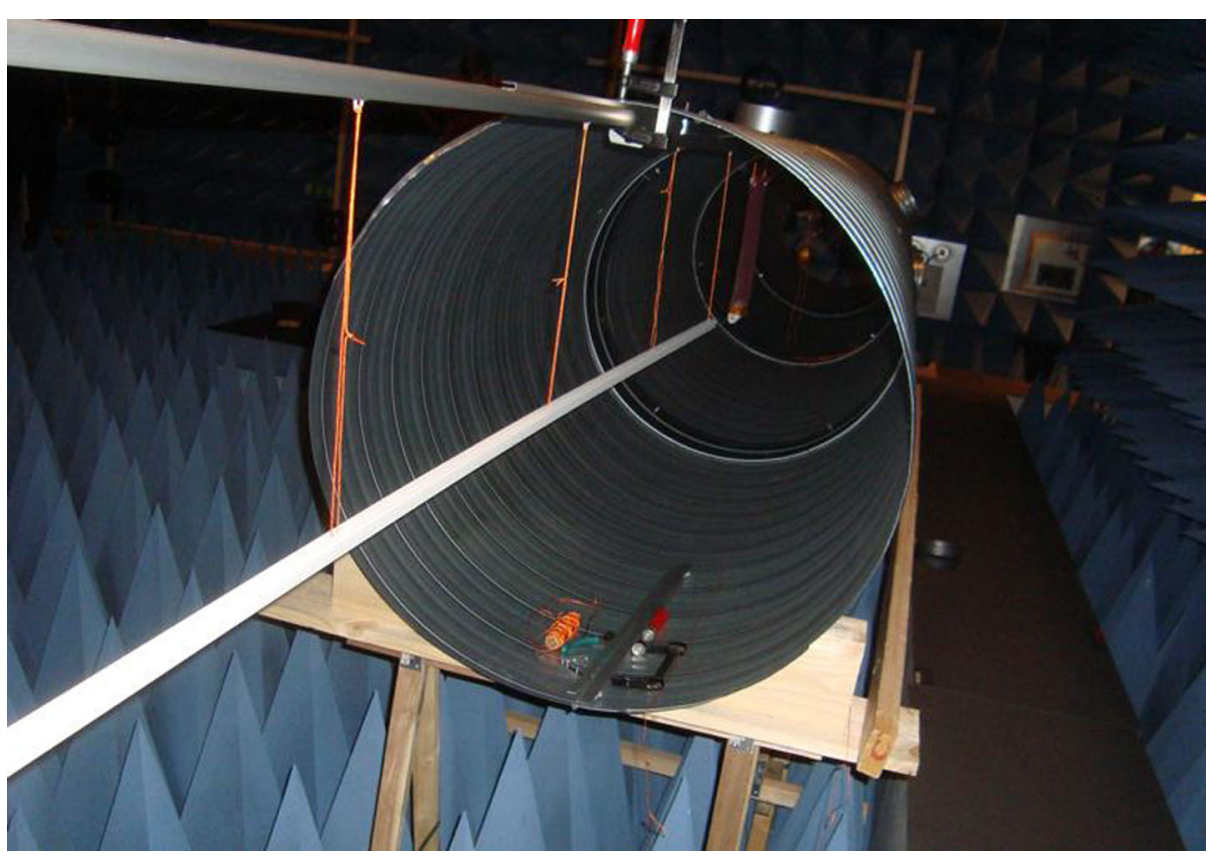

Fig. 32 Test setup for tests of FM17 BEB + boom cable + preamp in IRFU EMC chamber

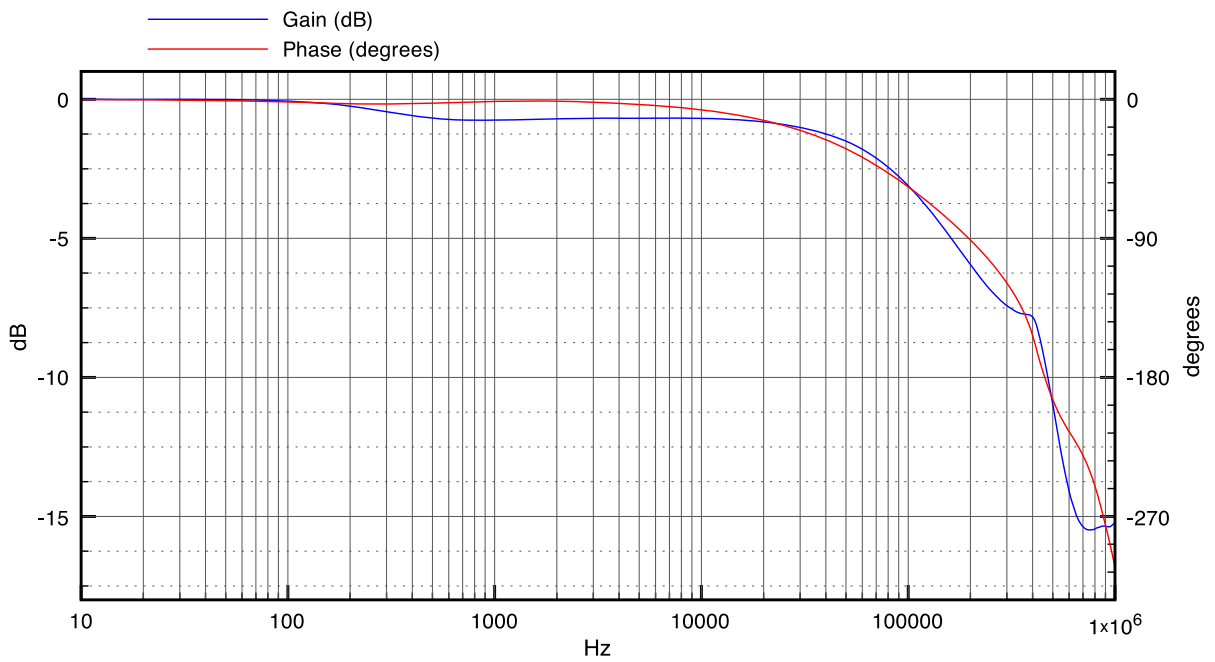

Fig. 33 Gain and phase plots for FM17 in IRFU EMC chamber, using input impedance $R=10 \mathrm{M} \Omega$ and $C=10.4 \mathrm{pF}$, and sending signal to both probe and cylinder

\section{In-flight Calibration}

Since it is impossible to completely mimic the space conditions during ground tests, the final tuning and calibration of the SDP electric field instrument will be done in orbit. This activity will start during the commissioning phase, when various combinations of bias current 


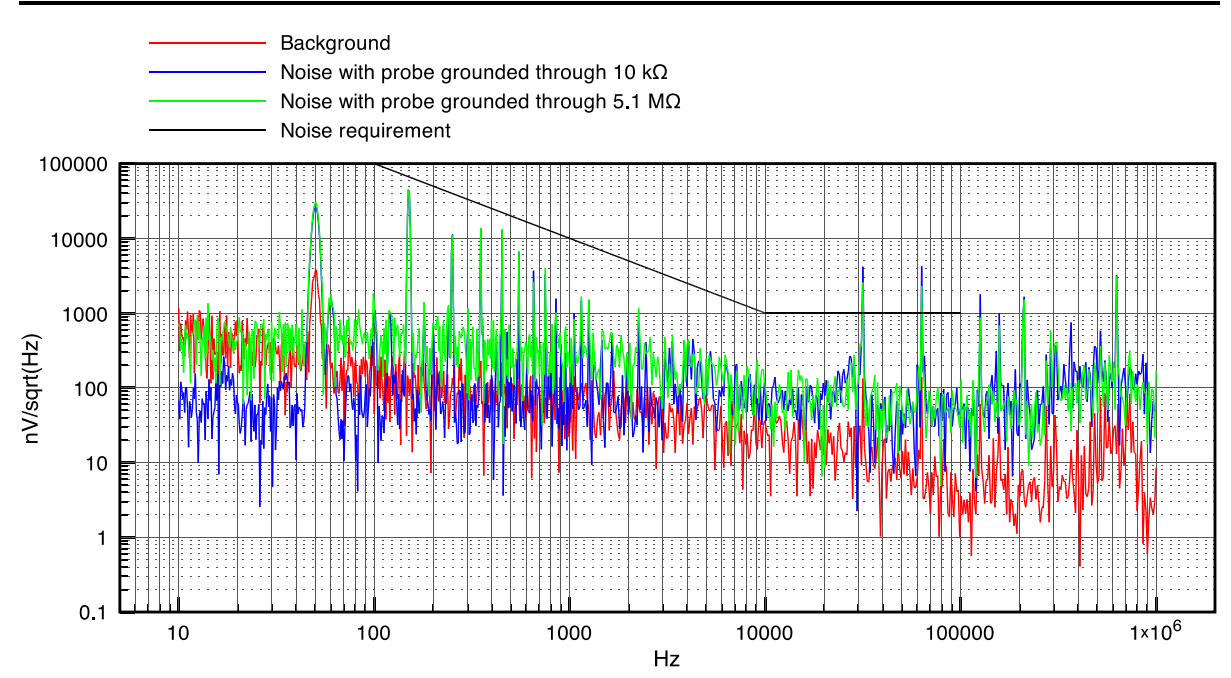

Fig. 34 Noise measurement of FM17 in IRFU EMC chamber. The noise is well below the requirements, as indicated by the black line

$I_{b}$, outer and inner guard voltages $V_{o g}$ and $V_{i g}$ will be tested. Tests will be done at different stages of the boom cable deployments, to gather information on the instrument characteristics as function of distance from the spacecraft body to the probes. Tests will also be done comparing SDP measurements with the ASPOC ion emitter off and on, and operating in different modes. Regular sweeps of the bias current during the entire mission will aid in determining the photoemission properties of the probes and in optimizing the operational bias current.

An important in-flight calibration method is to compare the measurements of the doubleprobe electric field instrument with other measurements of the electric field on the spacecraft. In many regions it will be possible to compare with the Electron Drift Instrument (EDI), which accurately measures the electric field components perpendicular to the ambient magnetic field. In other regions particle instrument measurements of the plasma drift velocity $\mathbf{v}_{d}$ can be used for direct comparisons of $\mathbf{E}$ and $\mathbf{v}_{d} \times \mathbf{B}$. Such comparisons will be used to derive the boom shortening factor and offsets to be used in the ground data processing to get the best values of the DC electric fields. Much of this work will benefit from experience gained from similar calibrations done of the electric field and wave instrument (EFW) on the Cluster mission (Khotyaintsev et al. 2014).

\section{Commissioning}

The commissioning of the SDP instrument comprises several steps:

- Opening of the doors on each of the 4 SDP deployers;

- Deployment of the 4 boom cables to $17 \mathrm{~m}$ length, in several steps;

- Spin-up of the spacecraft to $7 \mathrm{rpm}$ to deploy the thin wire to $1.75 \mathrm{~m}$ length;

- Deployment of the 4 boom cables to 22 and $41 \mathrm{~m}$ length for probe pairs $1+2$ and $3+4$, respectively, in several steps;

- Spin-up of the spacecraft to $6.1 \mathrm{rpm}$;

- Deployment of the 4 boom cables to $57 \mathrm{~m}$ length, in several steps; 


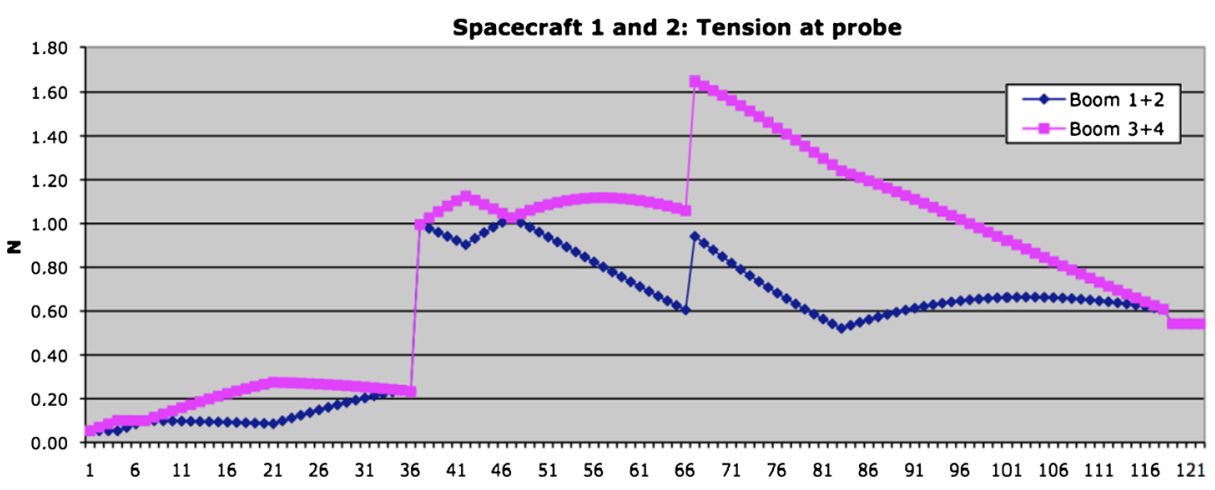

Fig. 35 Tension in thin wire during SDP boom deployment. The $\mathrm{x}$-axis is arbitrary step numbers. The spacecraft spin-up to $7 \mathrm{rpm}$ occurs at step 37, and all booms are fully deployed at step 119

- Adjustment of spacecraft spin rate to $3 \mathrm{rpm}$.

These operations will take place over a period of several weeks, and at each intermediate boom length, a number of diagnostic measurements will be made, with two main goals. The first is to determine optimum values of the bias current $I_{b}$ and the guard voltages $V_{o g}$ and $V_{i g}$. The second goal is to characterize the environment at different distances from the spacecraft, specifically to attempt to find the electric potential distribution around the spacecraft, with the commissioning period being the only opportunity to get such measurements at different boom lengths.

The yoyo mechanism containing the thin wire separating the preamp and the probe has been carefully tuned to match the centrifugal force during the SDP boom cable deployment. Figure 35 shows the tension in the thin wire during different stages of the boom cable deployment. The retracting force of the yoyo (cf. Fig. 21) is designed to be such that the yoyo stays stowed before the spacecraft spin-up to $7 \mathrm{rpm}$ at step 37 (while the tension stays below $0.29 \mathrm{~N}$ ), deploys fully at the spin-up (when the tension reaches $1.04 \mathrm{~N}$ ), and stays deployed thereafter (also when the centrifugal force drops to $0.53 \mathrm{~N}$ around step 83).

\section{Operational Modes, Telemetry, and Data Products}

\subsection{Operational Modes}

The SDP electric field instrument has only one basic operational mode, measuring the electric field and the individual probe potentials relative to the spacecraft. In contrast to other missions (e.g., Cluster), which also had the possibility to set a voltage to the probes and measure the resulting current (the Langmuir mode), SDP can only set the bias current to the probe and measure the voltage (the $E$-field mode). In its scientific operational mode, SDP will be operating with optimal values of the bias current $I_{b}$ and the outer and inner guard voltages $V_{o g}$ and $V_{i g}$. The bias current will be set to compensate for emitted photoelectrons (which dominate in sunlight), and/or collected ambient plasma electrons (dominating in eclipse) in an attempt to keep the probe potential near the plasma potential. The guard voltages will be adjusted to minimize the influence on the measurement of the electric field of photoelectrons emitted from the spacecraft, booms, and other parts of the SDP instrument. The values of $I_{b}, V_{o g}$, and $V_{i g}$ will largely be determined during commissioning, but 
will be checked and possibly modified regularly during the mission in order to account for changing solar UV flux and probe surface aging.

The instrument is also capable of performing an automatic sweep of the bias current, in order to get a current-voltage characteristic similar to that in Fig. 2. This capability will be exercised at regular intervals outside the main region of scientific interest to ensure that the operational value of $I_{b}$ is optimal.

\subsection{Telemetry}

The analog data from SDP are digitized in the FIELDS Digital Signal Processor (DSP). DSP contains digital filters and analog to digital converters running at up to 262144 samples/s. Normally, the dc output from the SDP electric field instrument to the telemetry are the probe potential differences $V_{12}$ and $V_{34}$ together with two individual probe signals $V_{1}$ and $V_{3}$. The sampling rates are $8 \mathrm{~s}^{-1}$ in slow survey, $32 \mathrm{~s}^{-1}$ in fast survey, and 1024, 8192, or $65536 \mathrm{~s}^{-1}$ in burst. In addition, a number of AC channels sampled at higher rates are available as spectra (in survey) or time series (in burst). Results from the bias current sweeps are transmitted separately. More information on the FIELDS telemetry is given in the companion paper (Torbert et al. 2014, this issue).

\subsection{Data Products}

After reception on the ground, SDP data will be combined with ADP data to yield the full electric field vector. Quicklook data products to be made available within a few hours include the dc electric field up to 32 samples/s, $E$-field spectra in the ranges $1-8000 \mathrm{~Hz}$ and $0.25-100 \mathrm{kHz}$, and the probe-spacecraft potential. The dc electric field will then be further calibrated by comparison with EDI and other measurements to yield the Level 2 electric field up to 65536 samples/s, in addition to the quicklook data, within 30 days. Finally, an elaborate algorithm of combining SDP, ADP and EDI electric field data, called BESTARG2, will yield high-quality, high time-resolution, electric field data, with error bars computed from the data, within a similar time frame. More information on the data products, including the algorithm BESTARG2, is given in the overall FIELDS companion paper (Torbert et al. 2014, this issue).

\section{Summary}

The SDP instrument, built as a collaborative effort between a number of scientific institutes, is a highly capable double-probe electric field instrument for the MMS spacecraft. It will produce high-accuracy (better than $0.5 \mathrm{mV} / \mathrm{m}$ ), high time-resolution (up to $32 \mathrm{ksam}$ ples/s) measurements in support of the scientific goals of the MMS mission. It has been fully and successfully tested and calibrated prior to spacecraft integration, both mechanically and electrically. Further calibration and fine-tuning to optimize the MMS electric field measurements will be done in orbit.

Acknowledgements The Swedish contributions to SDP were funded by the Swedish National Space Board. The US contributions to SDP were funded by NASA.

Open Access This article is distributed under the terms of the Creative Commons Attribution License which permits any use, distribution, and reproduction in any medium, provided the original author(s) and the source are credited. 


\section{References}

L.P. Block, C.-G. Fälthammar, P.-A. Lindqvist, G. Marklund, F.S. Mozer, A. Pedersen, T.A. Potemra, L.J. Zanetti, Electric field measurements on Viking: first results. Geophys. Res. Lett. 14, 435-438 (1987). doi:10.1029/GL014i004p00435

L.G. Blomberg, G.T. Marklund, P.-A. Lindqvist, F. Primdahl, P. Brauer, L. Bylander, J.A. Cumnock, S. Eriksson, N. Ivchenko, T. Karlsson, A. Kullen, J.M.G. Merayo, E.B. Pedersen, J.R. Petersen, EMMAthe electric and magnetic monitor of the aurora on Astrid-2. Ann. Geophys. 22, 115-123 (2004). doi:10.5194/angeo-22-115-2004

R.E. Ergun, S. Tucker, J. Westfall, K.A. Goodrich, D.M. Malaspina, D. Summers, J. Wallace, M. Karlsson, J. Mack, N. Brennan, B. Pyke, P. Withnell, R.B. Torbert, J. Macri, D. Rau, I. Dors, P.-A. Lindqvist, G. Olsson, C.M. Cully, The axial double probe and fields signal processing for the MMS mission. Space Sci. Rev. (2014, this issue). doi:10.1007/s11214-014-0115-x

U. Fahleson, Theory of electric field measurements conducted in the magnetosphere with electric probes. Space Sci. Rev. 7, 238-262 (1967). doi:10.1007/BF00215600

U. Fahleson, C.-G. Fälthammar, A. Pedersen, Ionospheric temperature and density measurements by means of spherical double probes. Planet. Space Sci. 22, 41-66 (1974). doi:10.1016/0032-0633(74)90122-6

G. Gustafsson, R. Boström, B. Holback, G. Holmgren, A. Lundgren, K. Stasiewicz, L. Åhlén, F.S. Mozer, D. Pankow, P. Harvey, P. Berg, R. Ulrich, A. Pedersen, R. Schmidt, A. Butler, A.W.C. Fransen, D. Klinge, M. Thomsen, C.-G. Fälthammar, P.-A. Lindqvist, S. Christenson, J. Holtet, B. Lybekk, T.A. Sten, P. Tanskanen, K. Lappalainen, J. Wygant, The electric field and wave experiment for the Cluster mission. Space Sci. Rev. 79, 137-156 (1997). doi:10.1023/A:1004975108657

G. Gustafsson, M. André, T. Carozzi, A.I. Eriksson, C.-G. Fälthammar, R. Grard, G. Holmgren, J.A. Holtet, N. Ivchenko, T. Karlsson, Y. Khotyaintsev, S. Klimov, H. Laakso, P.-A. Lindqvist, B. Lybekk, G. Marklund, F. Mozer, K. Mursula, A. Pedersen, B. Popielawska, S. Savin, K. Stasiewicz, P. Tanskanen, A. Vaivads, J.-E. Wahlund, First results of electric field and density observations by Cluster EFW based on initial months of operation. Ann. Geophys. 19, 1219-1240 (2001). doi:10.5194/angeo-19-1219-2001

Yu.V. Khotyaintsev, P.-A. Lindqvist, C.M. Cully, A.I. Eriksson, M. André, In-flight calibration of doubleprobe electric field measurements on Cluster. Geosci. Instrum. Method. Data Syst. 3, 143-151 (2014). doi:10.5194/gi-3-143-2014

G.T. Marklund, L.G. Blomberg, P.-A. Lindqvist, C.-G. Fälthammar, G. Haerendel, F.S. Mozer, A. Pedersen, P. Tanskanen, The double probe electric field experiment on Freja: experiment description and first results. Space Sci. Rev. 70, 483-508 (1994). doi:10.1007/978-94-011-0299-5_5

A. Pedersen, B. Lybekk, M. André, A. Eriksson, A. Masson, F.S. Mozer, P.-A. Lindqvist, P.M.E. Décréau, I. Dandouras, J.-A. Sauvaud, A. Fazakerley, M. Taylor, G. Paschmann, K.R. Svenes, K. Torkar, E. Whipple, Electron density estimations derived from spacecraft potential measurements on Cluster in tenuous plasma regions. J. Geophys. Res. 113, A07S033 (2008). 19 pp. doi:10.1029/2007JA012636

R.B. Torbert, C.T. Russell, W. Magnes, R.E. Ergun, P.-A. Lindqvist, O. Le Contel, H. Vaith, J. Macri, S. Myers, D. Rau, J. Needell, B. King, M. Granoff, M. Chutter, I. Dors, G. Olsson, Yu.V. Khotyaintsev, A. Eriksson, C.A. Kletzing, S. Bounds, B. Anderson, W. Baumjohann, M. Steller, K. Bromund, G. Le, R. Nakamura, R.J. Strangeway, H.K. Leinweber, S. Tucker, J. Westfall, D. Fisher, F. Plaschke, J. Porter, K. Lappalainen. The FIELDS instrument suite on MMS: scientific objectives, measurements, and data products. Space Sci. Rev. (2014, this issue). doi:10.1007/s11214-014-0109-8

K. Torkar, R. Nakamura, M. Tajmar, C. Scharlemann, H. Jeszenszky, G. Laky, G. Fremuth, C.P. Escoubet, K. Svenes, Active spacecraft potential control investigation. Space Sci. Rev. (2014, this issue). doi:10.1007/s11214-014-0049-3

K. Torkar, A.I. Eriksson, P.-A. Lindqvist, W. Steiger, Long term study of active spacecraft potential control. IEEE Trans. Plasma Sci. 36, 2294-2300 (2008). doi:10.1109/TPS.2008.2003134 